\title{
Steroid signaling in plants and insects-common themes, different pathways
}

\author{
Carl S. Thummel ${ }^{1}$ and Joanne Chory ${ }^{2,3}$ \\ ${ }^{1}$ Howard Hughes Medical Institute, Department of Human Genetics, University of Utah, Salt Lake City, Utah 84112 USA; \\ ${ }^{2}$ Howard Hughes Medical Institute, Plant Biology Laboratory, The Salk Institute for Biological Studies, La Jolla, California \\ 92037, USA
}

Outside of mammals, two model systems have been the focus of intensive genetic studies aimed at defining the molecular mechanisms of steroid hormone action-the flowering plant, Arabidopsis thaliana, and the fruit fly, Drosophila melanogaster. Studies in Arabidopsis have benefited from a detailed description of the brassinosteroid (BR) biosynthetic pathway, allowing the effects of mutations to be linked to specific enzymatic steps. More recently, the signaling cascade that functions downstream from BR production has been defined, revealing for the first time how the hormone can exert its effects on gene expression through a cell surface receptor and phosphorylation cascade. In contrast, studies of steroid hormone action in Drosophila began in the nucleus, with a detailed description of the transcription puffs activated by the steroid hormone 20-hydroxyecdysone (20E) in the giant polytene chromosomes. Subsequent genetic studies have revealed that these effects are exerted through nuclear receptors, much like mammalian hormone signaling. Most recently, genetic studies have begun to elucidate the ecdysteroid biosynthetic pathway which, until recently, remained largely undefined. Our current understanding of steroid hormone signaling in Arabidopsis and Drosophila provides a number of intriguing parallels as well as distinct differences. At least some of these differences, however, appear to be due to deficiencies in our understanding of these pathways. Below we discuss recent breakthroughs in defining the molecular mechanisms of BR biosynthesis and signaling in plants, and we compare and contrast this pathway with what is known about the mechanisms of ecdysteroid action in Drosophila. We raise some current questions in these fields, the answers to which may reveal other similarities in steroid signaling in plants and animals.

\section{Brassinosteroid biosynthesis and homeostasis}

Although plants and animals diverged more than 1 billion years ago, it is remarkable that polyhydroxylated

${ }^{3}$ Corresponding author.

E-MAIL chory@salk.edu; FAX 858-558-6379

Article and publication are at http://www.genesdev.org/cgi/doi/10.1101/ gad.1042102. steroidal molecules are used as hormones in both of these kingdoms, as well as in algae and fungi. Brassinosteroids (BRs), a class of plant-specific steroid hormones, control many of the same developmental and physiological processes as their animal and fly counterparts, including regulation of gene expression, cell division and expansion, differentiation, programmed cell death, and homeostasis. The regulation of these processes by BRs, acting together with other plant hormones, leads to the promotion of stem elongation and pollen tube growth, leaf bending and epinasty, root growth inhibition, proton-pump activation, and xylem differentiation (Mandava 1988; Clouse and Sasse 1998). In addition, useful agricultural applications have been found such as increasing yield and improving stress resistance of several major crop plants (Ikebawa and Zhao 1981; Cutler et al. 1991).

Although the existence and biological activity of these plant steroids had been described in a large body of literature, they only found their way into the mainstream of plant hormone biology a few years ago, when the available biochemical and physiological data were complemented by the identification of BR-deficient mutants of Arabidopsis (Clouse et al. 1996; Kauschmann et al. 1996; Li et al. 1996; Szekeres et al. 1996), pea (Nomura et al. 1999), and tomato (Bishop et al. 1999; Koka et al. 2000). Mutations in 8 loci of Arabidopsis and several additional loci in tomato and pea result in plants with reduced levels of BR biosynthetic intermediates and lead to distinct phenotypes (Bishop et al. 1996; Li et al. 1996; Szekeres et al. 1996; Choe et al. 1998a,b, 1999a,b, 2000; Klahre et al. 1998; Nomura et al. 1999; Kang et al. 2001). In Arabidopsis, loss-of-function mutations in these genes have pleiotropic effects on development. In the dark, the mutants are short, have thick hypocotyls and open, expanded cotyledons, develop primary leaf buds, and inappropriately express light-regulated genes. In the light, these mutants are dark green dwarfs, have reduced apical dominance and male fertility, display altered photoperiodic responses, show delayed chloroplast and leaf senescence, have reduced xylem content, and respond improperly to fluctuations in their light environment 
(Chory et al. 1991, 1994; Millar et al. 1995; Szekeres et al. 1996; Fig. 1). Such phenotypic differences between BRdeficient mutants and wild-type Arabidopsis plants indicate that these genes (and by inference, BRs) play an important role throughout Arabidopsis development. Exogenous application of brassinolide (BL, the most active $\mathrm{BR}$, and generally thought to be the endpoint of the biosynthetic pathway) leads to the normalization of their phenotypes. A biosynthetic pathway derived solely from biochemical studies provided an excellent framework for the characterization of these mutants, and was in turn confirmed and refined by their analysis (for review, see Clouse and Sasse 1998; Noguchi et al. 2000; Friedrichsen and Chory 2001; Fig. 1).

Because of their striking mutant phenotypes, which led to the identification of most BR biosynthetic genes, considerable progress has been made in understanding the mechanisms of BR homeostasis. Multiple control mechanisms for regulating the levels of BRs in plants have been identified, including regulation of biosynthesis, inactivation, and feedback regulation from the signaling pathway. BR-deficient mutants have helped to determine that $\mathrm{BL}$ is not synthesized via a simple linear biosynthetic pathway. Recently, two pathways, the early C-6 oxidation and late C- 6 oxidation pathways, were proposed for the biosynthesis of BL (Choi et al. 1996, 1997). In the early C-6 oxidation pathway, hydroxylation of the side chain occurs after $\mathrm{C} 6$ oxidation, whereas in the late C-6 oxidation pathway the hydroxylation of the side chain occurs before position 6 of the B-ring is oxidized. Feeding experiments with intermediates of both path- ways provided strong genetic evidence that both pathways operate in Arabidopsis (Fujioka et al. 1997; Choe et al. 1998a). A study with $d w f 4$ mutants suggests that 6-deoxo-cathasterone is a starting point for a new subpathway as this compound is able to rescue $d w f 4$ mutations (Choe et al. 1998a). Of note, DWF4, a C-22 hydroxylase, appears to be the major rate-limiting step in the BR biosynthetic pathway based on feeding studies and overexpression of DWF4 in transgenic plants (Choe et al. 2001). Similarly, 6-6 $\alpha$-hydroxycampestanol could also be a starting point for a different subpathway whose intermediates act as "bridging molecules" between the early and late C-6 oxidation pathways. One simple explanation for plants having multiple pathways of BL biosynthesis is that these subpathways might be differentially regulated by various environmental or developmental signals. A possible point for light-regulation of BR biosynthesis has very recently been identified and is indicated in red in Figure 1 (Kang et al. 2001). In addition, feeding experiments using det 2 and $d w f 4$ mutants have shown that BRs in the late C- 6 oxidation pathway are more effective in rescuing light phenotypes, whereas the BRs in the early C- 6 oxidation pathways show stronger activity in promoting hypocotyl elongation of darkgrown seedlings (Fujioka et al. 1997; Choe et al. 1998a).

Endogenous levels of BRs are increased in BR-signaling mutants, such as Arabidopsis bri1 and its orthologous mutants in tomato, pea, and rice (discussed below; Noguchi et al. 1999; Yamamuro et al. 2000; Bishop and Yokota 2001). These BR-insensitive mutants show the largest increases in the early C-6 oxidation BRs. In Ara-

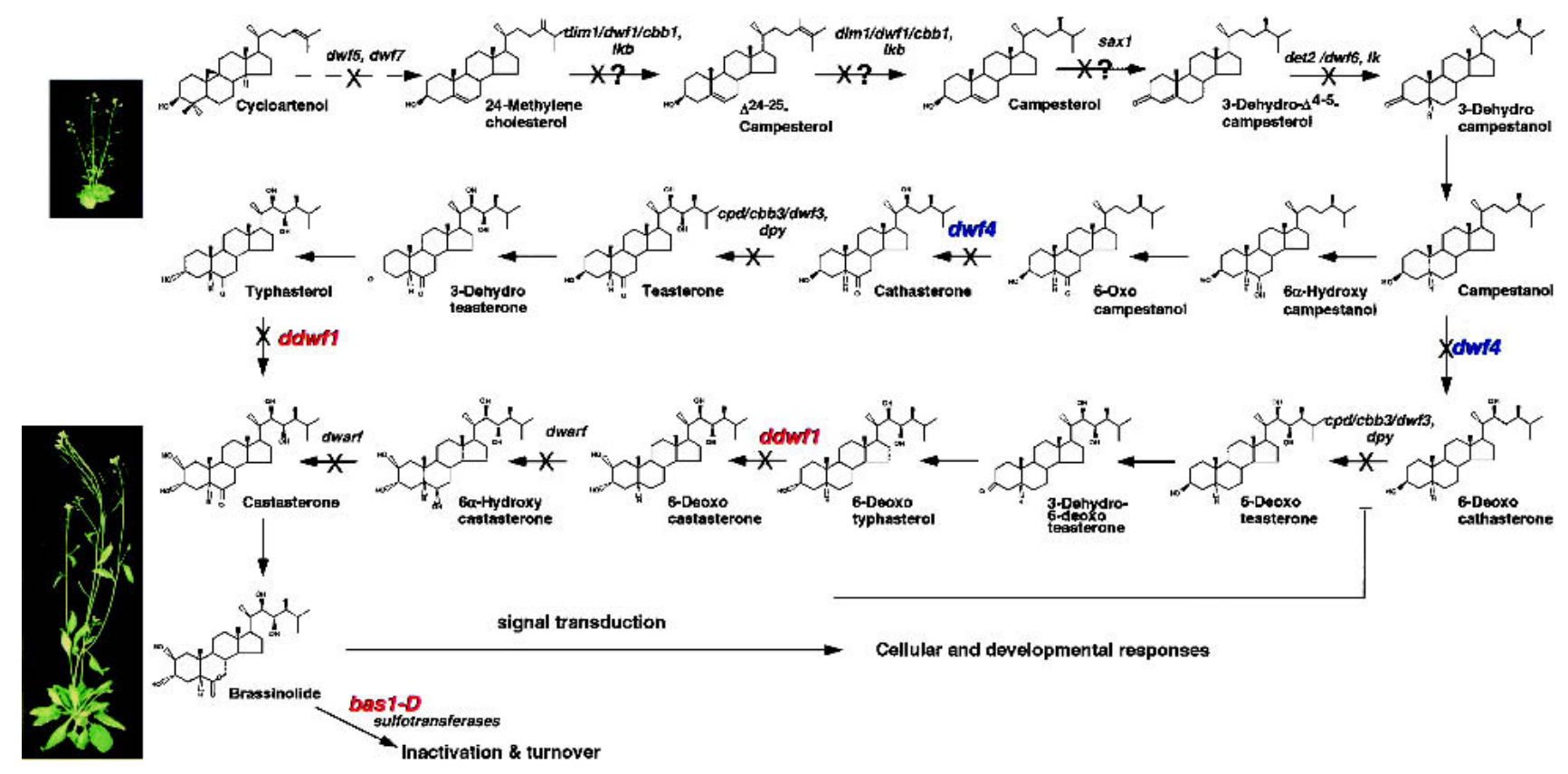

Figure 1. Proposed pathways of brassinolide biosynthesis and turnover. In the absence of the hormone, Arabidopsis plants are dwarfed and male-sterile (upper left corner). A wild-type plant is shown for comparison in the lower left corner (plants are photographed at the same scale). Mutants defining the various steps in the pathway are indicated. The major rate-limiting step, which is catalyzed by the C-22 hydroxylase encoded by the DWF4 gene, is shown in blue (Choe et al. 2001). Possible points of control by the light signaling pathways are indicated in red (Neff et al. 1999; Kang et al. 2001). 
bidopsis bri1 mutants, there is a large accumulation of not only castasterone and typhasterol, but also BL (Noguchi et al. 1999). Moreover, the CPD gene is negatively regulated by $\mathrm{BL}$ in a protein synthesis-dependent manner, and the expression of DWF4 is increased in both bri1 mutants and also in some BR biosynthetic mutants (Mathur et al. 1998; Noguchi et al. 1999). Therefore, functional BR signaling is necessary for BR homeostasis through the regulation of at least some of the BR biosynthetic genes. At least one regulatory gene involved in this feedback control, BZR1, has been identified, and is discussed in greater detail below (Wang et al. 2002).

Metabolic inactivation through modification is another important mechanism in the control of the steadystate level of active hormones. Sulfotransferases have been shown to modulate the activity of steroid hormones in animals and it has recently been shown that a sulfotransferase from Brassica catalyzes the O-sulfonation at position 22 of 24-epicathasterone in vitro and abolishes its biological activity (Strott 1996; Rouleau et al. 1999). Hydroxylation is another important modification leading to inactivation of a number of hormones. The Arabidopsis BAS1 gene encodes a cytochrome P450 (cyp72B1), which when overexpressed results in a phenotype that is similar to BR-deficient mutants (Neff et al. 1999). BAS1-overexpressing mutants have reduced levels of the late intermediates in the BL biosynthetic pathway and accumulate 26-hydroxybrassinolide in feeding experiments. These results are consistent with the interpretation that BAS1 encodes a steroid 26-hydroxylase that is involved in inactivating BL or one of its precursors. Thus, there are multiple mechanisms for controlling the levels of BRs within plants.

It should be noted that key steps in plant and animal steroid biosynthetic pathways are highly conserved, and it can be expected that insects will also utilize many of the same enzymes. In mammals, steroid hormones are synthesized from cholesterol via pregnenolone through a series of reactions that modify the ring structure and the side chain of the sterol. Similarly, BRs are derived from cycloartenol through campesterol, a major phytosterol via multiple oxidation steps (Fig. 1). The most striking example of functional conservation between mammalian and plant steroid biosynthetic enzymes described to date is for the steroid $5 \alpha$-reductases (Russell and Wilson 1994). Recombinant Arabidopsis steroid 5 $\alpha$-reductase, encoded by the DET2 gene, can be expressed in human embryonic kidney 293 cells, where it is capable of reducing several mammalian steroids with a 3 -oxo, $\delta^{4,5}$ structure, including testosterone, androstenedione, and progesterone (Li et al. 1997). Somewhat surprisingly, the Arabidopsis DET2 shows similar affinities for animal steroids as do the mammalian steroid $5 \alpha$-reductases, with apparent $\mathrm{Km}$ values in the micromolar range. Moreover, either of the human isoforms can rescue the pleiotropic phenotypes of det2 by substituting for DET2 in BR biosynthesis, suggesting that the human isozymes will have similar affinities for BRs as DET2 (Li et al. 1997). Thus, both the structural and functional conservation between DET2 and mammalian steroid $5 \alpha$-reductases suggest that they evolved from a common ancestor. Surprisingly, however, it should be noted that there is no good evidence for a $5 \alpha$-reductase activity in insects. $5 \alpha$ compounds have no biological activity in arthropods and have not been detected among the secretory products from molting glands (Bergamasco and Horn 1980; Blais et al. 1996). This suggests that the genes encoding steroid $5 \alpha$-reductases have been lost in the insect lineage.

\section{Ecdysteroid biosynthesis in Drosophila}

Whereas our understanding of BR signaling was established from a detailed description of the BR biosynthetic pathway, allowing mutants to be rapidly linked to specific enzymatic steps in this process, ecdysteroid biosynthesis has-until recently-been poorly defined. Several excellent reviews of the ecdysteroid biosynthetic pathway have been published (Grieneisen 1994; Rees 1995; Gilbert et al. 2002) and thus we will limit our discussion here to an overview of this pathway, with an emphasis on the current breakthroughs afforded by recent biochemical genetic studies in Drosophila.

Like most insects, which depend on plant steroids as a source of cholesterol, Drosophila obtains this key precursor of steroid biosynthesis from its diet. Plant steroids are converted into cholesterol in the gut, through side chain dealkylation steps in most, if not all plant-eating insects, and released into the circulatory system. Conversion of cholesterol into ecdysone occurs through a series of enzymatic steps within the prothoracic gland.

The first step in this pathway is the stereospecific removal of the $7 \beta$ - and $8 \beta$-hydrogens of cholesterol to form a key sterol intermediate, 7-dehydrocholesterol (Fig. 2). The 7,8-dehydrogenase that catalyzes this reaction is a microsomal P450 that is present in the prothoracic gland, although the enzyme itself has not yet been identified (Grieneisen et al. 1993; Gilbert et al. 2002). 7-dehydrocholesterol is an abundant and constitutive sterol in the prothoracic gland. It has been proposed that the translocation of 7-dehydrocholesterol from the endoplasmic reticulum to the mitochondria, where it may be oxidized to downstream steps in the pathway, is a rate-limiting step in ecdysteroid biosynthesis (Gilbert et al. 2002). Studies of the ecdysteroid-deficient mutant ecd1 suggest that the corresponding gene product could play a critical role in this proposed translocation event (Warren et al. 1996).

Conversion of 7-dehydrocholesterol to the next step(s) in the pathway remain poorly understood and are largely hypothetical, represented by the "black box" reactions (Fig. 2). A number of studies suggest that the end product from the "black box" reactions is 2,22,25-trideoxyecdysone, also referred to as the ketodiol intermediate (Fig. 2). This compound is converted into ecdysone through a series of three well-characterized hydroxylation steps, resulting in the sequential formation of 2,22-dideoxyecdysone (ketotriol), 2-deoxyecdysone and, finally, ecdysone (Gilbert et al. 2002; Fig. 2). Although ecdysone is the primary ecdysteroid secreted by the prothoracic 

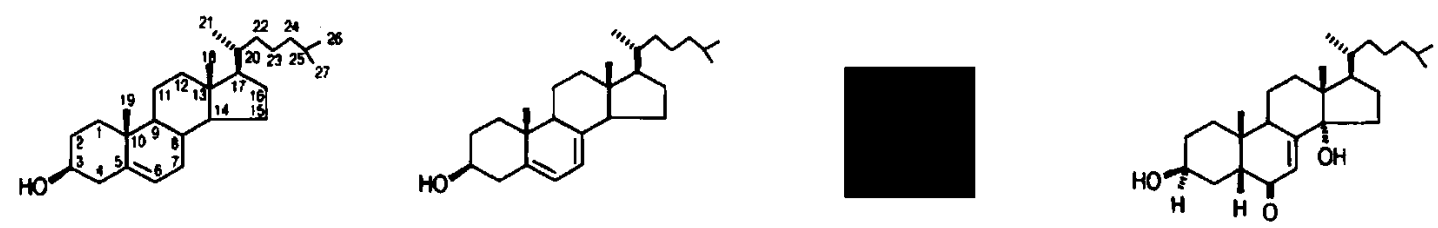

CHOLESTEROL

7-DEHYDROCHOLESTEROL

"BLACK BOX"

$(2,22,25 \mathrm{dE})$

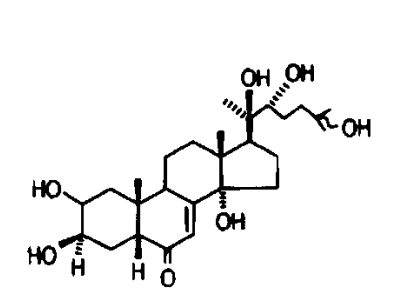

20-HYDROXYECDYSONE

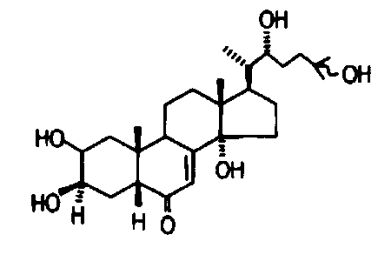

ECDYSONE

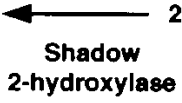

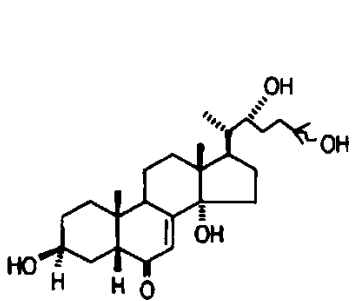

$\downarrow$

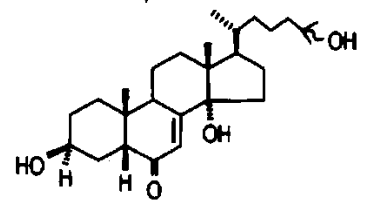

2-DEOXYECDYSONE

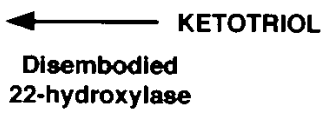

Figure 2. Schematic representation of the ecdysteroid biosynthetic pathway in Drosophila. The chemical structures and names of the steps in the ecdysteroid biosynthetic pathway are depicted, along with the enzymes encoded by the dib and shadow genes. See text for details. Adapted with permission from Figure 1 of Warren et al. (2002; copyright 2002, National Academy of Sciences, USA).

gland of Drosophila, it is modified by an enzyme in peripheral tissues into the more biologically active form of the hormone, 20E (Winter et al. 1999). Pulses of 20E are responsible for most, but not all (see below), biological responses to ecdysteroids during the insect life cycle.

Larval molting, adult leg morphogenesis, cuticle production, and some ecdysteroid-regulated gene expression require an ecdysteroid pulse-that is, a rise and subsequent fall in ecdysteroid titer-for their proper regulation (Richards 1976; Fristrom and Fristrom 1993; Riddiford 1993). Thus, like plants, where the levels of BL are reduced through metabolic inactivation, there is good evidence for controlled inactivation of 20E in Drosophila, with at least one cytochrome $\mathrm{P} 450$ in this pathway (Gilbert et al. 2002). As with ecdysteroid biosynthesis, however, no enzymes have yet been purified in this catabolic pathway and no genes have yet been identified, although some P450 genes are expressed at high levels when 20E is being inactivated (Hurban and Thummel 1993; White et al. 1999). Given that 84 cytochrome P450 genes are present in the Drosophila genome sequence, the stage is set to identify those members of this family that play a role in modulating the $20 \mathrm{E}$ titer during development (FlyBase 1999).

Thus, in sharp contrast to our detailed understanding of the BR biosynthetic pathway, the molecular mechanisms of ecdysteroid biosynthesis and degradation have remained largely undefined. A recent breakthrough in this field, however, arose from genetic studies in Drosophila, identifying several of the enzymes in the ecdysteroid biosynthetic pathway and, perhaps more importantly, providing insights into the regulation and function of the corresponding genes during insect development.
Recent insights into the molecular mechanisms of ecdysteroid biosynthesis

Mutations in the ecdysteroid biosynthetic pathway trace their origin to what, at first glance, might seem an unlikely source-the classic genetic screens by NüssleinVolhard, Weischaus and colleagues to characterize embryonic pattern formation in Drosophila (Jürgens et al. 1984; Nüsslein-Volhard et al. 1984; Wieschaus et al. 1984). The mutants in these studies were classified based on their patterns of cuticular markers, with one set distinguishing itself by a complete absence of larval cuticle. These mutants are referred to as the Halloween class based on their unusual appearance, and escaped further study until recently when one member of the Halloween class was cloned and characterized-disembodied or dib (Jürgens et al. 1984; Chavez et al. 2000). Mutations in dib result in severe defects in major embryonic morphogenetic movements, including head involution, dorsal closure, and gut development, as well as a block in cuticle production. Reasoning that ecdysteroids are required for cuticle deposition during later stages of the life cycle, Chavez et al. (2000) investigated the ecdysteroid titer in these mutants and discovered a dramatic reduction in the levels of both ecdysone and 20E. Consistent with this phenotype, the expression of an early 20E-inducible gene, IMP-E1, is significantly reduced in dib mutant embryos. The authors isolated the gene corresponding to $d i b$ and discovered that it encodes a new member of the cytochrome P450 superfamily that is expressed selectively in the prothoracic gland of Drosophila. These observations immediately suggested an explanation for the effects of the dib mutation on ecdysteroid levels, leading to the proposal that it encodes a key enzyme in the hor- 
mone biosynthetic pathway (Chavez et al. 2000). This hypothesis was recently confirmed by biochemical characterization of the Dib protein, showing that it acts as the 22-hydroxylase, catalyzing the conversion of 2,22dideoxyecdysone to 2-deoxyecdysone (Warren et al. 2002; Fig. 2).

This discovery had wider ramifications-suggesting that other members of the Halloween class of genes might function in the ecdysteroid biosynthetic pathway, potentially defining each step in the series. Indeed, shadow mutants display phenotypes similar to those of $d i b$, and the shadow gene has been shown to encode a P450 family member that is selectively expressed in the prothoracic gland (Warren et al. 2002). Biochemical studies have demonstrated that Shadow acts as the 2-hydroxylase in the biosynthetic pathway, directing the synthesis of ecdysone (Fig. 2). Recent work has indicated that spook, phantom, and shade mutants also display defects in ecdysteroid biosynthesis and appear to encode P450 enzymes of the same class as those defined by dib and shadow (Warren et al. 2002). It is possible that some of these P450s will direct the synthesis of unexpected ecdysteroid intermediates, revealing branches in the pathway similar to those present in BR biosynthesis. In addition, the levels of dib and shadow mRNA fluctuate with the molting cycle, suggesting that their transcriptional control may provide insight into the feedback mechanisms that modulate the hormone titer (Warren et al. 2002). Further characterization of the Halloween class of genes should provide a molecular framework for understanding the ecdysteroid biosynthetic pathway as well as our first insights into the genetic regulation of hormone titers during insect development.

\section{BR signaling and the control of cell expansion}

Genetic approaches for BR signaling mutants in Arabidopsis have been both informative and challenging. Despite extensive genetic screening for loss-of-function BRinsensitive mutants, only one locus, bri1, has been identified (Clouse 1996; Kauschmann et al. 1996; Li and Chory 1997; Noguchi et al. 1999; Friedrichsen et al. 2000). bri1 mutants have identical phenotypes to brassinosteroid-deficient mutants, but these phenotypes cannot be rescued by addition of BL to the growth medium. The BRI1 gene is predicted to encode a protein with an extracellular domain containing 25 leucine-rich-repeats (LRRs), interrupted by a 70-amino-acid island domain, a single transmembrane domain and an intracellular serine/threonine kinase domain ( $\mathrm{Li}$ and Chory 1997). Several lines of study indicate that BRI1 is a critical component of the BR receptor complex. First, BRI1 protein is constitutively expressed in young growing cells, which is consistent with its expected mode of action (Friedrichsen et al. 2000). Second, a chimeric receptor composed of BRI1's extracellular domain and the kinase domain of Xa21, a rice LRR receptor kinase for disease resistance, confers BL-dependent pathogen responses to rice cells (He et al. 2000). In addition, both membrane fractions and immunoprecipitates containing BRIl bind ${ }^{3} \mathrm{H}-\mathrm{la}-$ beled BL specifically and such binding is greatly reduced in plants harboring mutations in the extracellular domain (Wang et al. 2001). The kinase domain of BRIl displays serine/threonine kinase activity in vitro (Friedrichsen et al. 2000; Oh et al. 2000), and BL treatment in plants induces BRIl autophosphorylation (Wang et al. 2001). Thus, BRIl perceives the BR signal through its extracellular domain and initiates a signal transduction cascade through its cytoplasmic kinase activity. This is in contrast to fly and animal steroid nuclear receptors that directly activate target gene expression upon ligand binding. It should be noted that there are no reports documenting that BRIl binds BL directly. Thus, it is formally possible that BL is presented to BRIl on a carrier protein, or that other proteins are involved in BL perception (Li et al. 2001a; Bishop and Koncz 2002). Nonetheless, BRIl appears to be a critical component of the major binding activity for brassinosteroids.

Other components of the BR signal transduction pathway have been identified by their gain-of-function phenotypes. Overexpression of $B A K 1$, a gene encoding another leucine-rich repeat receptor kinase, partially suppresses the phenotype of a weak bri1 allele (Li et al. 2002). BAK1 was also identified by its in vitro interaction with BRIl and has been shown to modulate BR signaling (Li et al. 2002; Nam and Li 2002). BAK1 can be coimmunoprecipitated with BRI1 from plants, and has been proposed to act as a coreceptor for BRs, yet this remains to be shown. A semidominant BR response mutant, bin2, has a phenotype similar to bri1 mutants (Li et al. 2001b). The bin2 phenotype results from a hypermorphic mutation in a glycogen synthase kinase-3, suggesting that wild-type BIN2 is a negative regulator of BR signaling ( $\mathrm{Li}$ and Nam 2002; Perez-Perez et al. 2002). Two mutants, bes1 and bzr1, were identified as suppressing bri1 phenotypes, as well as being resistant to brassinazole, a BR biosynthesis inhibitor (Wang et al. 2002; Yin et al. 2002). BES1 and BZR1 encode closely related proteins $(89 \%$ identity) that accumulate in the nucleus following BR treatment. Identical dominant mutations identified in both genes stabilize the respective proteins and increase their accumulation in the nucleus in the absence of BRs (Wang et al. 2002; Yin et al. 2002). Moreover, in the absence of BRs, BES1 and BZR1 can be phosphorylated by the negative regulator BIN2, resulting in their turnover, which apparently is mediated via the $26 \mathrm{~S}$ proteasome (He et al. 2002; Yin et al. 2002). BZR1 and BES1 appear to be involved in the regulation of BLregulated genes, although they have no obvious DNAbinding domains. bes1-D mutants significantly overexpress BL-regulated genes in the absence of brassinosteroids, and have phenotypes that are consistent with enhanced elongation of cells in a number of tissues (Yin et al. 2002). In contrast, bzr1-D mutants are semidwarf and are involved in the negative feedback control of BR biosynthetic gene expression (Wang et al. 2002).

Unlike bri1 loss-of-function mutations, mutants in components of the BR signaling pathway do not mimic the phenotypes of steroid deficient mutants. Functional redundancy resulting from extensive gene duplications 
in Arabidopsis is one probable explanation (The Arabidopsis Genome Initiative 2000). Loss-of-function mutations in $B A K 1$ produce only weak phenotypes, perhaps due to the residual action of other LRR-type kinases. BIN2 is one of ten GSK3/Shaggy-like kinases in Arabidopsis and cosuppression studies indicate that reduced BIN2 levels have only a weak effect on plant growth. BES1 and BZR1 are part of a six-member family, and their loss-of-function phenotypes have not been reported.

The signaling pathway downstream of BRI1 may be branched. The Arabidopsis det3 mutant is a dwarf mutant with a deetiolated phenotype in the dark (Cabrera y Poch et al. 1993); it is also insensitive to BL applications in hypocotyls (Schumacher et al. 1999). DET3 encodes the large C subunit (an assembly subunit) of the vacuolar proton-ATPase, which is found on a number of endomembranes as well as the plasma membrane (Ho et al. 1993; Finbow and Harrison 1997; Schumacher et al. 1999). In the dark, the hypocotyl elongation defect of det3, a very weak allele, is somewhat specific to BRs because the mutant hypocotyls can elongate in response to gravity when grown upside down (Schumacher et al. 1999). Previous studies have indicated that BR-induced hypocotyl elongation of cucumbers was dependent on membrane-bound ATPase activity (Mandava 1988). Thus, it seems likely that BRs may regulate cell elongation via regulated assembly of the V-ATPase, which in turn might promote the uptake of water into the vacuole. However, the V-ATPase appears to act in several signaling pathways, only one of which is the cell elongation response induced by BRs.

The basic design of a BR signaling pathway, linking events at the plasma membrane to changes in gene expression in the nucleus, is beginning to be elucidated, yet several gaps in our knowledge remain. Several mechanistic questions are outstanding, most importantly, what is the functional BL receptor? What are the substrates for BRI1's BL-induced kinase activity? What are the major signaling components that act between BRI1 and BIN2? What proteins do BZR1/BES1 interact with to regulate gene expression in the nucleus? And finally, where does the specificity of BL action come from? Given the rapid pace of gene discovery in this pathway over the past year, continued molecular genetic studies should soon answer some of these questions.

\section{BRs regulate gene expression}

Early studies on the molecular mechanisms of BR signaling demonstrated that BR-induced responses require de novo protein synthesis (Mandava 1988) and BL-treatment induces synthesis of both mRNAs and proteins (Clouse 1996). A number of genes whose expression is regulated by BL applications have been identified and several have predicted functions in cell expansion, cell division, and assimilate partitioning (for review, see Clouse and Sasse 1998; Bishop and Yokota 2001; Friedrichsen and Chory 2001). Perhaps the best studied are a number of xyloglucan endotransglycosylases (XETs), in- cluding the BRU1 gene from elongating soybean epicotyls (Zurek and Clouse 1994; Clouse 1996; Oh et al. 1998). The expression level of $B R U 1$ correlates with the extent of BL-promoted stem elongation and the accumulation of the BRU1 transcript parallels the BL-mediated increases in plastic extensibility of the cell wall (Zurek et al. 1994). Moreover, a linear relationship has been observed between $\mathrm{BL}$ concentrations and extractable XET activities in BL-treated soybean epicotyls, strongly suggesting an involvement of BRU1 in BL-stimulated stem elongation (Oh et al. 1998). A BL-regulated XET has also been identified in Arabidopsis. The TCH4 gene encodes an XET whose expression is increased within $30 \mathrm{~min}$ of $\mathrm{BL}$ treatment, with a maximum at $2 \mathrm{~h}$. In contrast to soybean $B R U 1$, whose RNA levels are regulated posttranscriptionally, BL-regulated TCH4 expression occurs at the transcriptional level (Xu et al. 1995).

Very recently, several studies documented the extent of BL-regulated gene expression in Arabidopsis, as well as identified the first BL early response genes (Friedrichsen et al. 2002; Mussig et al. 2002; Yin et al. 2002). Surprisingly, the number of BL-regulated genes is relatively small ( $\sim 50$ genes differentially expressed of 8000 sampled on the oligoarray), and the magnitude of their induction is also small, on the order of two to fivefold changes. However, the changes in expression of these genes appear to be meaningful, as their mRNAs are altered by BL-treatment and the changes in gene expression require a functional BR receptor (Friedrichsen et al. 2002; Yin et al. 2002). Moreover, their degree of change by BL is enhanced in a constitutively active BR response pathway mutant (see below; Yin et al. 2002). Among the 30 BLinduced genes are a few that encode transcription factors and BAS1; seven genes encode putative cell wall-associated proteins, including XETs, endo-1,4- $\beta$-glucanases, polygalacturonase, pectin methylesterase, and expansin, all of which have been implicated in cell expansion (Yin et al. 2002). Several identified BL-induced genes are known to be induced by another plant hormone, auxin (Mussig et al. 2002; Yin et al. 2002). A second study corroborated these general conclusions, although the experiments were done with BR-deficient mutants (Mussig et al. 2002). This study also documented a number of genes whose expression is reduced by BL-treatments. Among the BL-repressed genes were genes encoding several transcription factors, as well as genes encoding BR biosynthetic enzymes, supporting the negative feedback pathway for BR biosynthesis.

The most direct evidence for the physiological significance of these small changes in gene expression comes from a recent study that identified three BL early response genes (Friedrichsen et al. 2002). These three genes encode closely related basic helix-loop-helix transcription factors, $B E E 1, B E E 2$, and $B E E 3$, whose expression is induced within $30 \mathrm{~min}$ of BL treatment in the absence of new protein synthesis and requires a functional BL receptor. Reverse genetic studies suggest that these three genes are required for full BR signaling response, as triple knockout mutant plants have weak BR signaling and developmental phenotypes, while overexpression of BEE1 
results in $\mathrm{BR}$ hypersensitivity. Although there is evidence that $B E E 1, B E E 2$, and $B E E 3$ play roles in multiple hormone signaling pathways, a known BR-regulated gene involved in cell expansion is up-regulated in the $B E E 1$-overexpressing lines, suggesting that these transcription factors play an important role in activating downstream genes controlling BL-induced responses (Friedrichsen et al. 2002). Thus, in analogy to ecdysteroid signaling, brassinosteroids may lead to changes in physiology through a hierarchy of gene expression changes. In sharp contrast to the well-characterized numerous changes in gene expression following ecdysteroid pulses, however, the magnitude of BR-mediated gene expression changes are small and appear to largely affect cell expansion processes. The identification of BR-responsive promoter elements would significantly enhance the molecular dissection of BR-regulated gene expression.

\section{A model for BR signaling in cell expansion processes}

A model for BR signaling, connecting cell surface events with changes in nuclear gene expression, can be proposed (Fig. 3). The model proposes that BRI1 is the BL receptor or a critical component of a "receptor complex", which may also contain BAK1. Upon perception of BL, BRIl signals through a phosphorylation cascade that involves both changes in gene expression and rapid growth induction responses that involve the V-ATPase. These pathways act separately to affect cell expansion pro- cesses, as BL-regulated gene expression still occurs in the det3 mutant background. In the absence of $\mathrm{BL}$, the negative regulator BIN2 phosphorylates BES1 and BZR1, and this phosphorylation leads to rapid turnover of these proteins. In the presence of BL, signaling through BRI1 inactivates BIN2 by an unknown mechanism and results in increased levels of dephosphorylated BES1 and BZR1 and their nuclear accumulation. The mutations in bes1 and bzr1 appear to stabilize the proteins and this results in BL-independent nuclear accumulation and constitutive BR responses. Because bes 1 mutants show enhanced BL-regulated gene expression, it appears that BES1 is involved in regulating gene expression changes in the nucleus. Likewise, bzr1 mutants have reduced stature and accumulation of BR biosynthetic intermediates, as well as decreased expression of a BR biosynthetic gene, suggesting a role for BZR1 in negative feedback regulation of BR biosynthetic genes. Thus, this pathway looks mechanistically very similar to the Wnt signaling pathway in animals, in which $\beta$-catenin is phosphorylated and turned over by a GSK-3 kinase in the absence of Wnt, and in which $\beta$-catenin is dephosphorylated, stabilized and shuttled to the nucleus in the presence of Wnt $/ \mathrm{Ca}$ digan and Nusse 1997; Huelsken and Birchmeier 2001; Sharpe et al. 2001; Woodgett 2001). It will be of interest to discover the mechanism by which BZR1 and BES1 differentially regulate gene expression. Presumably, this mechanism will involve specific interactions with transcription factors yet to be identified.

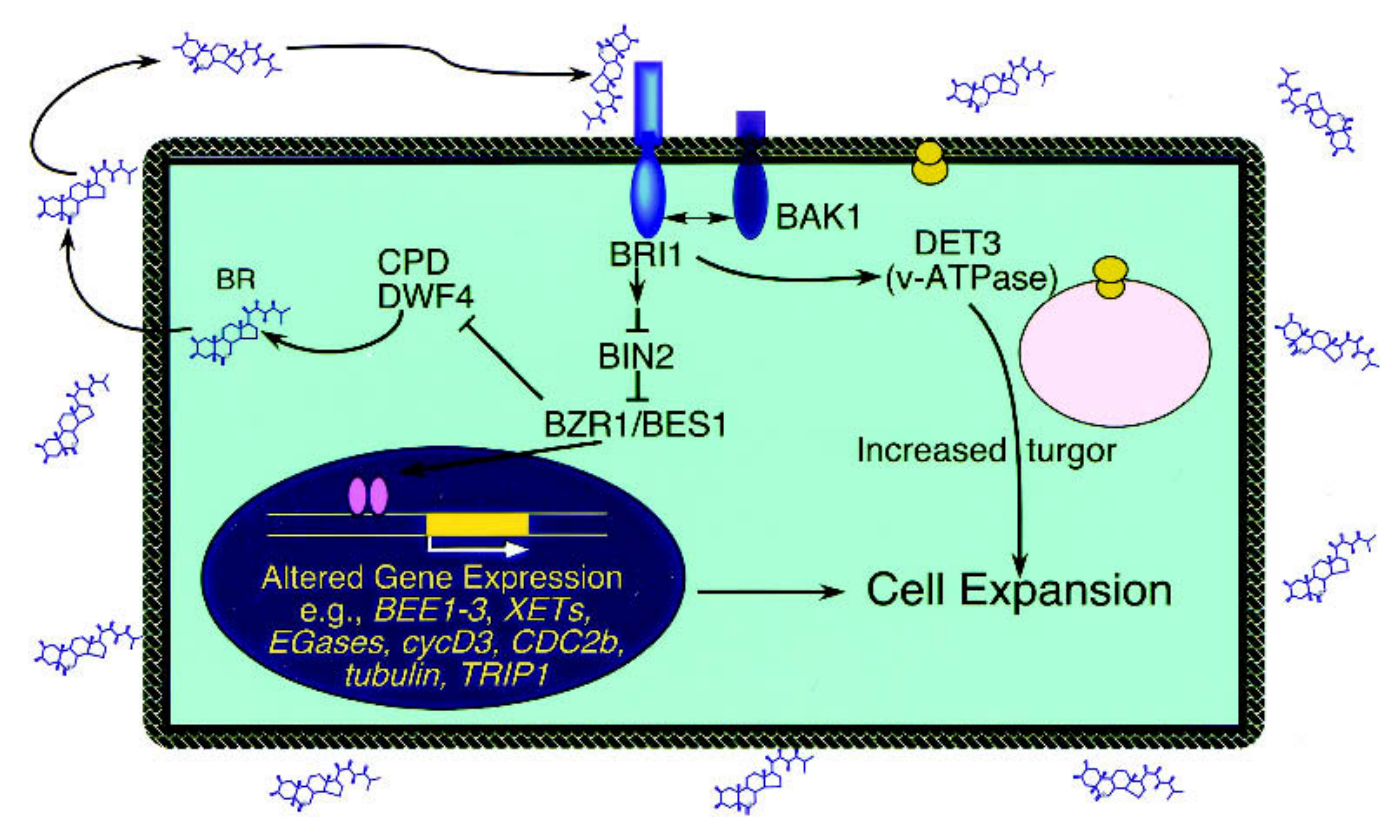

Figure 3. A model for BR signaling in Arabidopsis. In the model, BRIl is the BL receptor or a critical component of a receptor complex that may also involve BAK1. Upon perception of BL, BRI1 signals through a phosphorylation cascade that includes both changes in gene expression and rapid growth induction responses that involve the V-ATPase. These pathways act separately to affect cell expansion processes, as BL-regulated gene expression still occurs in the det 3 mutant background. In the absence of $\mathrm{BL}$, the negative regulator BIN2 phosphorylates BES1 and BZR1 and this phosphorylation leads to rapid turnover of these proteins. In the presence of BL, signaling through BRI1 inactivates BIN2 and results in increased levels of dephosphorylated BES1 and BZR and their nuclear accumulation. Presumably, BES1 and BZR1 then interact with other proteins to regulate the expression of downstream target genes. See the text for additional details. 


\section{Similar steroid-regulated biological pathways in plants and insects?}

Ecdysteroids exert widespread effects on insect growth and development. These include roles in morphogenesis, proliferation, programmed cell death, cuticle synthesis, oogenesis, and developmental timing (Robertson 1936; Riddiford 1993). It is intriguing that some aspects of these pathways share features in common with the wide range of developmental and physiological responses to BRs in plants, which also include promotion of cell division, expansion, and programmed cell death, and modulation of reproductive development. For example, both $\mathrm{BL}$ and ecdysteroids are required for cell shape changes associated with maturation-although they exert this effect in different ways. As described above, BL induces the expression of a range of cell wall-associated proteins that are implicated in cell expansion, providing a molecular basis for understanding the role of BRs in directing cell elongation and plant growth. Similarly, ecdysteroids trigger the morphogenesis of adult structures during metamorphosis through coordinated changes in cell shape manifested at the level of the actin cytoskeleton (von Kalm et al. 1995). It is interesting to speculate that these two responses reflect the basic architectural differences that define plant and animal cells. Thus, the presence of a rigid cell wall in plants demands changes at the level of cell wall-associated proteins to control changes in overall cell shape. Similarly, the integrity of an insect cell is defined by an internal cytoskeleton, which is the target for ecdysteroid-triggered changes in cell shape.

Another similarity in steroid responses between plants and insects is programmed cell death. Ecdysteroids trigger the massive death of larval tissues during the early stages of metamorphosis, ridding the animal of these obsolete tissues to make way for their adult counterparts (Robertson 1936). This response has been extensively studied in Drosophila and shown to occur by autophagy with hallmark features of apoptosis, including DNA fragmentation and caspase activation (Jiang et al. 1997; Jochova et al. 1997; Lee and Baehrecke 2001). 20E exerts this effect in the larval salivary glands through a regulatory cascade that results in stage- and tissue-specific induction of key death genes that include the E93 early gene, reaper, hid, ark (APAF-1/CED-4 homolog), dronc (apical caspase), and croquemort (related to CD36; Baehrecke 2002; Bender 2003).

There is evidence that BRs induce programmed cell death during xylogenesis. The specialized xylem vessels that conduct water through plants are made up of individual dead cells called tracheary elements (Roberts and McCann 2000). The BR-deficient Arabidopsis mutants $c p d$ and $d w f 7$ have abnormal xylem, implicating the hormone in xylogenesis, although these phenotypes have not been examined in detail (Szekeres et al. 1996; Choe et al. 1999b). In addition, Clouse and Zurek observed that exogenously supplied BL promotes both tracheary element differentiation and cell division in cultured tuber explants of Jerusalem artichoke (Clouse and Zurek
1991). Using a zinnia system (Zinnia elegans L. cv Canary Bird) in which single mesophyll cells can differentiate directly into tracheary elements, it was observed that exogenously supplied uniconazole (an inhibitor of both gibberellin and BR biosynthesis) prevents uncommitted cells from transdifferentiating into tracheary elements, and that BL but not gibberellin overcomes this inhibition (Iwasaki and Shibaoka 1991). Moreover, BRs appear to act specifically during the final stage of xylogenesis, which involves secondary wall formation and cell death. During this time, the levels of BRs rise dramatically (Yamamoto et al. 2001). These data suggest that endogenous BRs initiate the final step of cytodifferentiation, a programmed cell death response. The molecular mechanisms by which BRs exert this effect, however, remain to be determined. Key death genes have not been found in plant genomes, and little is known of the mechanism of programmed cell death in plant systems.

\section{E exerts its effects directly on gene expression through a nuclear receptor heterodimer}

Steroid hormones exert their effects in both plants and insects through changes in gene expression. The means by which the hormonal signal is transduced to direct these changes in gene activity, however, appears to be dramatically different. While Arabidopsis has been shown to utilize a cell surface LRR kinase as a BL receptor, the Drosophila ecdysteroid receptor is a heterodimer of two members of the nuclear receptor superfamily, the EcR ecdysteroid receptor and the RXR ortholog, USP (Yao et al. 1992, 1993; Thomas et al. 1993). The EcR/USP heterodimer functions very much like RXR heterodimers act in vertebrates, providing a valuable model system for understanding the molecular mechanisms of hormone action in animals. EcR/USP binds ecdysteroids with high affinity and directly induces target gene transcription through canonical hormone response elements (Koelle et al. 1991; Yao et al. 1992, 1993; Thomas et al. 1993). A detailed review has been recently published that outlines our current understanding of EcR/USP regulation and function (Riddiford et al. 2000).

\section{The genetic response to $20 \mathrm{E}$ is significantly larger than that induced by $B L$ in plants}

Our understanding of the molecular mechanisms of ecdysteroid action trace back to the now classic studies of the puffing patterns of the giant larval salivary gland polytene chromosomes. This work provided our first insights into eukaryotic gene regulation at a time when molecular approaches toward this goal were almost nonexistent. Pioneering studies by Clever and Karlson (1960) and Becker (1959) were later refined by Ashburner (1974), who used cultured larval salivary glands treated with $20 \mathrm{E}$ to carefully characterize the puffing response to the hormone. These studies provided the first indication that the genetic response to ecdysteroids is highly complex, comprising well over 100 different 20E-inducible 
puffs. Moreover, these studies allowed Ashburner and colleagues to postulate the existence of a steroid-triggered regulatory cascade- the first such regulatory pathway to be described in eukaryotes (Ashburner et al. 1974). The Ashburner model proposed that 20E rapidly and directly induces a small set of early regulatory genes, represented by about a half dozen early puffs in the polytene chromosomes. The protein products of these early puff genes were proposed to exert two opposing regulatory functions-to repress their own expression, self-attenuating the regulatory response to the hormone, and inducing a large set of late secondary-response puff genes. The late puff genes, in turn, were thought to function as effectors that control the eventual biological responses to ecdysteroids.

Extensive molecular studies over the past 15 years have provided strong support for the Ashburner model of ecdysteroid action. This work has been extensively reviewed and is beyond the scope of this discussion (Russell and Ashburner 1996; Thummel 1996; Richards 1997; Segraves 1998; Bender 2003). Rather, we wish to focus here on the similarities and differences between the genetic response to ecdysteroids in insects and that induced by BL in Arabidopsis. As described above, microarray studies have provided our first glimpse of the complexity of BL-regulated gene expression, which is smaller than might have been anticipated from the response in flies-with $\sim 50$ genes out of 8000 assayed showing a significant change in expression level. This contrasts with the complexity of the puffing response in the salivary glands, but even more so with the results of microarray analysis. In an initial study, $31 \%$ of 465 ESTs tested were induced threefold or greater in parallel with the late larval pulse of ecdysteroids (White et al. 1999). Assuming that there are $\sim 14,000$ genes in the Drosophila genome, this could extrapolate to as many as 4000 ecdysteroidinducible genes, with the caveat that this is only based on a temporal correlation with the late larval ecdysteroid pulse.
The number of steroid-inducible genes that encode transcription factors in Drosophila also exceeds that predicted by microarray analysis in Arabidopsis. A dozen transcription factor-encoding genes have been shown to be induced directly by $20 \mathrm{E}$, some of which correspond to the early puffs characterized by Ashburner (BR-C, E74, and $E 75$; Table 1). Other genes that encode transcription factors have been implicated in ecdysteroid response pathways by virtue of their mutant phenotypes, including forkhead and cryptocephal (Hewes et al. 2000; Renault et al. 2001). In addition, microarray studies have detected a number of transcription factor encoding-genes that show increased expression in correlation with ecdysteroid pulses, including DMef2, bagpipe, tinman, and short-sighted (White et al. 1999). It thus seems likely that the number of steroid-inducible transcriptional regulators is significantly greater in Drosophila than the number discovered to date in Arabidopsis.

Another hallmark of BR signaling is the relatively small changes in gene activity, with only an approximately two- to fourfold induction by hormone. This is shared by the BEE1, BEE2, and BEE 3 transcriptional regulators that are induced by BL. Interestingly, a similar fold induction is seen for about half of the early 20E-inducible transcription factors that have been examined (Table 1). The remaining early genes show a more dramatic induction (several orders of magnitude) from an undetectable basal level. This class of highly-inducible transcriptional regulators has not yet been identified in BL signaling pathways.

The current data thus indicate that the genetic response to ecdysteroids in Drosophila is at least an order of magnitude greater than that induced by BL in Arabidopsis. This is, perhaps, not surprising when one considers the biological differences in these steroid response pathways. Although BL is required for overall growth and development in plants, there is no parallel with the rapid and massive change of body plan that is orchestrated by ecdysteroids during the onset of insect meta-

Table 1. 20E-inducible genes that encode transcription factors in Drosophila

\begin{tabular}{|c|c|c|c|c|}
\hline Gene & Puff & Fold-induction & $\begin{array}{c}\text { Protein } \\
\text { class }\end{array}$ & References \\
\hline$B R-C$ & 2B5 & $\sim 10$-fold & zinc fingers & (DiBello et al. 1991; Bayer et al. 1996) \\
\hline crol & & $\sim 2$-fold & zinc fingers & (D'Avino and Thummel 1998) \\
\hline DHR3 & & $>100$-fold & nuclear receptor & (Koelle et al. 1992; Horner et al. 1995) \\
\hline DHR39 & & $\sim 10$-fold & nuclear receptor & (Ayer et al. 1993; Ohno and Petkovich 1993; Horner et al. 1995) \\
\hline DHR78 & & $\sim 2$-fold & nuclear receptor & (Fisk and Thummel 1995) \\
\hline DHR96 & & $\sim 2$-fold & nuclear receptor & (Fisk and Thummel 1995) \\
\hline$E c R$ & $42 \mathrm{~A}$ & $\sim 2$-fold & nuclear receptor & (Koelle et al. 1991; Karim and Thummel 1992) \\
\hline E74 & $74 \mathrm{EF}$ & $>100$-fold & ETS domain & (Burtis et al. 1990) \\
\hline E75 & $75 \mathrm{~B}$ & $>100$-fold & nuclear receptor & (Segraves and Hogness 1990; Karim and Thummel 1992) \\
\hline$E 78$ & $78 \mathrm{C}$ & $>100$-fold & nuclear receptor & (Stone and Thummel 1993; Russell et al. 1996) \\
\hline E93 & $93 \mathrm{~F}$ & 10- to 100 -fold & PSQ domain & (Baehrecke and Thummel 1995; Siegmund and Lehmann 2002) \\
\hline$K r-h$ & & $\sim 5$-fold & zinc fingers & (Pecasse et al. 2000) \\
\hline
\end{tabular}

The corresponding early puff is listed, when known. Direct induction is inferred from cycloheximide studies and/or speed of induction by $20 \mathrm{E}$ in cultured third instar larval organs. The fold-induction is approximate, and is derived from steady-state mRNA levels in organs cultured from late third instar larvae. References are cited for both the fold-induction in cultured larval organs and the class of encoded protein. 
morphosis. It is easy to imagine that this complex transformation requires greater complexity at the level of hormone-induced gene activity, accounting for the widespread effects of $20 \mathrm{E}$ seen at the levels of polytene chromosome puffs and microarray analysis.

\section{Evidence for redundant genetic pathways in ecdysteroid signaling}

As described above, genetic studies of BR signaling in Arabidopsis have been greatly complicated by the high degree of genetic redundancy in this system. In contrast to plants, the use of forward genetic screens for defining ecdysteroid response pathways has only been recently exploited and only on a limited basis (Gotwals and Fristrom 1991; Gates and Thummel 2000; Pecasse et al. 2000). It is thus too early to draw firm conclusions regarding the degree of redundancy in ecdysteroid signaling pathways. The available results from reverse genetic studies in Drosophila, however, indicate that redundancy may be more prevalent than is currently appreciated. This has been most evident from genetic characterization of Drosophila nuclear receptor family members. Almost half of these genes appear to be regulated by $20 \mathrm{E}$ and expressed during the onset of metamorphosis, implicating them as regulators in the ecdysteroid-triggered genetic cascades (Thummel 1995). A number of genetic studies have supported this model. However, null mutations in several of these genes have no effect on viability or fertility: DHR39, E78, and E75B (Russell et al. 1996; Horner and Thummel 1997; Bialecki et al. 2002). Similarly, the DHR3 nuclear receptor is sufficient to repress early gene transcription, and thus has been considered as a candidate for the ecdysteroid-inducible repressor of the early genes predicted by the Ashburner model (White et al. 1997). Strong loss-of-function DHR3 mutants, however, show no effects on the timing of early gene repression (Lam et al. 1999). A similar model was proposed for $E 75 B$ inhibition of $\beta F T Z-F 1$ induction by $D H R 3$ based on a gain-of-function study, but this model was not supported by the loss-of-function mutant (White et al. 1997; Bialecki et al. 2002). In this case, there is a good candidate for a redundant activity with E75B-the E78B orphan nuclear receptor. These proteins are coexpressed, belong to the same subfamily of nuclear receptors (Rev-erb), and lack a complete DNA binding domain. Construction of $E 75 B ; E 78 B$ double mutants would provide a test of this proposed genetic redundancy. Genetic studies of $E c R, B R-C$, and $E 75$ also uncovered internal functional redundancy between the different isoforms encoded by these complex loci (Bayer et al. 1997; Bender et al. 1997; Bialecki et al. 2002). It thus appears that some aspects of ecdysteroid response pathways are buffered by genetic redundancy, although it is not as pervasive as has been encountered in Arabidopsis. One reason for this difference could be the greater number of genes in the Arabidopsis genome, which appears to have expanded through enlargement of gene families (The Arabidopsis Genome Initiative 2000).

\section{Regulation of ecdysteroid signaling outside the nucleus}

As described above, studies of ecdysteroid action have focused almost entirely on the nucleus. This is due to the observation that the EcR/USP heterodimer resides at specific binding sites on chromosomes, even in the absence of ligand, and exerts its effects almost exclusively through changes in gene activity (Riddiford et al. 2000). In spite of this focus, there is growing evidence that ecdysteroid signaling can be modulated in the cytoplasm, although none of these effects can be linked to a pathway that resembles the phosphorylation cascade triggered by BL in Arabidopsis. EcR/USP DNA binding activity requires interactions with a chaperone complex, proteins that normally reside in the cytoplasm, although it is not clear where this interaction occurs within the cell (Arbeitman and Hogness 2000). USP has also been shown to be phosphorylated; however, no effect has been demonstrated on its activity in vivo (Song and Gilbert 1998).

An additional level for modulating ecdysteroid action outside of the nucleus is through metabolic inactivation of the hormone-a level of regulation that is known to influence BL signaling (see above). It is likely that similar pathways are active in Drosophila, mediated by specific P450 enzymes that inactivate 20E, although these enzymes remain to be identified (Gilbert et al. 2002). Interestingly, one of the early 20E-inducible puffs described by Ashburner may also contribute to modulating ecdysteroid levels within the cell, thereby indirectly affecting receptor function. This gene, E23, encodes a member of the ABC family of transporters, enzymes that are involved in the active transport of small compounds (Hock et al. 2000). Gain-of-function studies indicate that E23 can act as a general negative regulator of ecdysteroid signaling, down-regulating the levels of early gene induction by 20E. The authors propose that it may exert this effect by transporting 20E outside of the cell, reducing the effective concentration of the hormone (Fig. 4). Future studies should provide a test of this interesting model.

A study by Champlin and Truman (2000) provides another possible link with BL signaling, demonstrating rapid and direct effects of $20 \mathrm{E}$ that occur independently of nuclear gene expression. These authors show that 20E promotes neuroblast proliferation during metamorphosis in part by suppressing nitric oxide production. This effect is rapid (<15 $\mathrm{min}$ ) and occurs in the absence of protein synthesis or transcription, hallmarks of a nongenomic effect. Aside from providing one of the best examples of nongenomic signaling by steroid hormones, this paper also raises the possibility of a novel 20E receptor that exists either on the cell surface or in the cytoplasm (Fig. 4). Given the precedent of the BL receptor in Arabidopsis, it is intriguing to speculate that this receptor could be a LRR receptor kinase. Identifying how $20 \mathrm{E}$ exerts this effect on nitric oxide production could provide new insights into the mechanisms of steroid action in animals as well as a parallel with the BL signal transduction pathway in plants. 


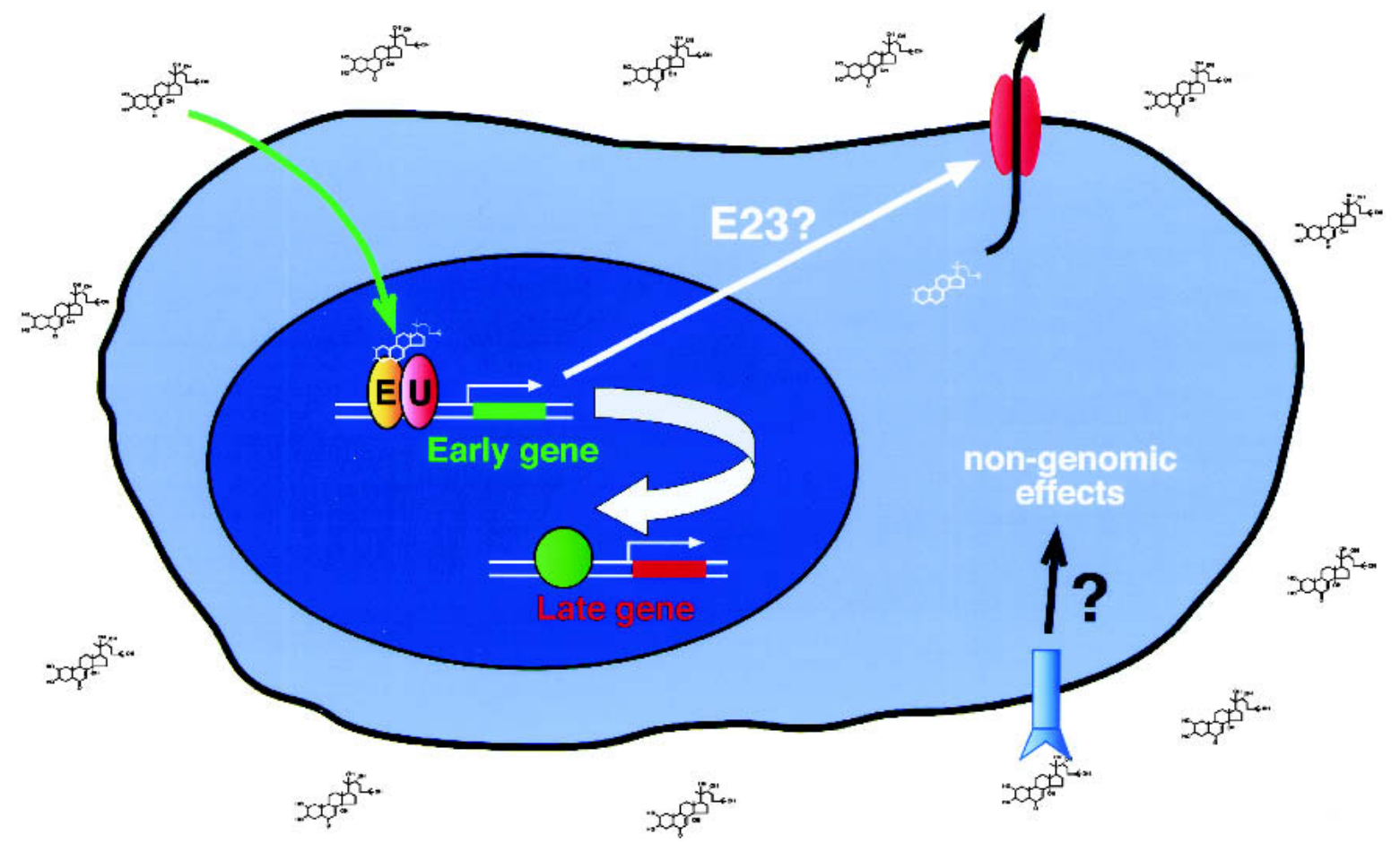

Figure 4. Mechanisms of ecdysteroid action in Drosophila. Ecdysteroids primarily exert their effects in the nucleus, through the EcR/USP heterodimer (E, U). The hormone-receptor complex directly induces early gene transcription. A subset of the early genes encode transcription factors that induce late gene expression. Two possible parallels with BL action in plants are depicted. A cell surface ecdysteroid receptor may mediate the nongenomic effects reported by Champlin and Truman (2000). A postulated role for the E23 transporter protein in reducing the intracellular concentration of ecdysteroids is also depicted (Hock et al. 2000).

\section{Insect hormone receptors that remain to be} identified-possible future ties to plants

As mentioned above, BRs can act synergistically or antagonistically in combination with other plant hormones, including auxin, ethylene, cytokinin, and ABA (Mandava 1988; Friedrichsen and Chory 2001; Friedrichsen et al. 2002). These effects can be seen at the level of gene regulation, as described above for BEE1, BEE2, and BEE3 expression, or at the level of specific biological responses. Similarly, the sesquiterpenoid juvenile hormone (JH) has been shown to modify the effects of ecdysteroids in insects, determining the nature of an ecdysteroid-triggered molt (Riddiford 1996). Unfortunately, this response is not seen in the larvae of higher Diptera such as Drosophila, and thus little is known about the molecular mechanisms of $\mathrm{JH}$ action during the molts. $\mathrm{JH}$ can, however, interact with ecdysteroids in Drosophila pupae, functioning through the 20E-inducible early gene $B R-C$ (Restifo and Wilson 1998; Zhou and Riddiford 2002). It has been proposed that USP may function as a $\mathrm{JH}$ receptor (Jones et al. 2001), but this is not consistent with the structure of the USP ligand binding domain (Billas et al. 2001; Clayton et al. 2001), leaving it unclear how the $\mathrm{JH}$ signal is transduced in insects.

Evidence is also accumulating for other systemic hormone signaling pathways that act either in parallel with $20 \mathrm{E}$, or in conjunction, to dictate specific biological re- sponses and effects on gene expression. Champlin and Truman (1998) have shown that a high titer pulse of ecdysone can drive the extensive proliferation of neuroblasts that takes place during early pupal development in the hornworm Manduca sexta. This is the first evidence that ecdysone, and not 20E, is responsible for a specific response in insects. Previous studies have shown that ecdysone is several orders of magnitude less active than $20 \mathrm{E}$, leading to the conclusion that it is an inactive precursor to the active hormone, 20E (Ashburner 1971; Cherbas et al. 1980; Gilbert et al. 2002). This data by Champlin and Truman raise the interesting possibility that ecdysone can act as a hormone in its own right. It is unlikely, however, that this signal is transduced through the EcR/USP heterodimer, which shows only very low transcriptional activity in response to this ligand (Baker et al. 2000). The discovery of a distinct receptor for ecdysone provides the next key step in understanding how this hormone might exert its effects on insect development.

Studies of ecdysteroid-regulated gene expression in Drosophila have also provided evidence for hormone signaling pathways that may act independently of 20E. Several studies have identified a large-scale coordinate switch in gene expression midway through the third larval instar-an event that has been referred to as the midthird instar transition (Andres and Cherbas 1992). It is not clear whether this response is triggered by one or 
more low titer pulses of ecdysteroid that may occur at this stage, in response to another hormonal signal, or in a hormone-independent manner (Richards 1981; Andres et al. 1993). Similarly, the let-7 and miR-125 micro RNAs are induced at the onset of metamorphosis in Drosophila in tight temporal correlation with the E74A early mRNA, but not in apparent response to 20E (A. Bashirullah, A. Pasquinelli, A. Kiger, N. Perrimon, G. Ruvkun, and C.S. Thummel, in prep.). The discovery of the signals and receptor(s) that mediate these responses should provide significant new directions in our understanding of insect physiology as well as provide new opportunities to link the mechanisms of hormone action in Drosophila with BR signaling pathways in plants.

\section{Coevolution of plants and insects: Phytoecdysteroids may act as natural pesticides}

Any discussion of the unity of life on earth should include how the predator/prey relationship of animals and plants have influenced their evolution. In this regard, it is remarkable that plants have developed a biosynthetic pathway to produce ecdysteroids with potent biological activity in insects. These phytoecdysteroids are present in 5\%-6\% of plant species tested (Imai et al. 1969; Dinan 1998) although most, if not all, species of plants appear to have the capacity to produce at least low levels of these compounds, including Arabidopsis thaliana (Dinan et al. 2001). The levels of phytoecdysteroids vary significantly between different plant species, between individuals within a species, as well as between different parts of a plant, season, habitat, and developmental stage, complicating our understanding of their possible biological functions (Dinan 2001). 20E is the most abundant phytoecdysteroid identified in the plant kingdom, although many other ecdysteroids, including ponasterone, ecdysone, cyasterone, and makisterone $\mathrm{A}$, have also been detected. Ponasterone, makisterone A, 20E, and cyasterone are highly efficacious in insect systems, including Drosophila (Ashburner 1971; Cherbas et al. 1980; Baker et al. 2000). Indeed, much of our current understanding of insect endocrinology has been established by using ecdysteroids purified from plant sources where they are highly abundant. Although the enzymatic pathway for phytoecdysteroid synthesis remains largely unknown, many modifications in these compounds are similar to those found in other plant triterpenoids, including BRs, suggesting that some parts of these synthetic pathways may be shared (Dinan 2001).

Phytoecdysteroids can act as antifeedants for at least some insect species, deterring them from preying on a plant apparently through taste receptors that respond to ecdysteroids (Jones and Firn 1978; Tanaka et al. 1994; Descoins and Marion-Poll 1999). Better evidence, however, is accumulating that phytoecdysteroids act as natural pesticides, disrupting the development of their larval hosts (Lafont et al. 1991; Dinan 1998). Addition of ecdysone, 20E, or ponasterone A to the diets of different insect species can interfere with a range of ecdysteroidregulated developmental responses, causing defects such as growth inhibition, supernumerary larval instars, and premature pupariation (Dinan 2001). Intriguingly, laboratory studies have demonstrated that insects which usually feed on plants with high levels of phytoecdysteroids tend to be more resistant to the effects of ecdysteroids in their diet, implying the existence of a metabolic pathway that can detoxify these compounds (for review, see Dinan 1998). Moreover, ecdysteroid levels in spinach are inducible by mechanical or insect damage to the roots, suggesting that this may be a defense response to injury (Schmelz et al. 1998, 1999). In spite of the questions that remain in our understanding of phytoecdysteroid synthesis and function, it seems that these compounds have no detrimental effects on mammals, being present in crop plants that humans have consumed for centuries. This observation provides a strong impetus to increase our understanding of the possible effects of these compounds on plant-insect interactions. Increasing phytoecdysteroid levels in crop plants may provide a means of exploiting these naturally occurring compounds as pesticides with obvious benefits for crop production.

\section{Plants and insects: Using different pathways to accomplish similar goals}

In both plants and animals, steroid hormones are synthesized via a cascade of cytochrome P450 enzymes, resulting in one or more compounds that have high biological activity. Interestingly, from a common biosynthetic pathway that was presumably shared by their common unicellular ancestor, the mechanisms of steroid signal transduction appear to have evolved independently in plants and insects, similar to other signaling pathways that have been characterized in these systems (Meyerowitz 2002). It is remarkable, however, that in spite of divergent signal transduction mechanisms, both plants and insects have evolved convergent uses for this ancient family of polyhydroxylated steroids in coordinating their overall development. In a further twist, plants also appear to have exploited this evolutionary conservation with insects, diverting part of their steroid biosynthetic pathway toward the production of potent ecdysteroids that could be used to fight off insect predators. Thus, it is possible that the steroid biosynthetic and signal transduction pathways may be coming back together and are now coevolving in some lineages. The final effect of these steroid hormones is to alter patterns of gene expression within target cells, controlling specific biological responses. Moreover, at least part of these effects are mediated through steroid-triggered regulatory cascades in both plants and insects.

It is possible that the apparent differences between the mechanisms of steroid signaling in plants and insects could result from the gaps in our understanding of steroid action in these systems and that further studies will reveal new parallels between these pathways. Most significantly, the identification of BRIl as a steroid receptor in Arabidopsis provides a new paradigm for hormone signal transduction, indicating that small lipophilic hor- 
mones can act through a cell surface LRR kinase, independently of the large and well-studied superfamily of nuclear receptors. The outlines of the BL and ecdysteroid signaling pathways are clearly in place and it remains for future studies to determine whether more dichotomies will be identified in these systems, or whether new regulatory links will emerge that span the plant and animal kingdoms.

\section{Acknowledgments}

We thank L. Dinan, L. Gilbert, and J. Warren for helpful discussions and critical comments on the manuscript, and A. Bashirullah, T. Kozlova, J. Umen, J. Nemhauser, and Y. Yin for comments on the manuscript. J. Chory and C.S. Thummel are Investigators with the Howard Hughes Medical Institute.

\section{References}

Andres, A.J. and Cherbas, P. 1992. Tissue-specific ecdysone reponses: Regulation of the Drosophila genes Eip28/29 and Eip40 during larval development. Development 116: 865-876.

Andres, A.J., Fletcher, J.C., Karim, F.D., and Thummel, C.S. 1993. Molecular analysis of the initiation of insect metamorphosis: A comparative study of Drosophila ecdysteroid-regulated transcription. Dev. Biol. 160: 388-404.

Arbeitman, M.N. and Hogness, D.S. 2000. Molecular chaperones activate the Drosophila ecdysone receptor, an RXR heterodimer. Cell 101: 67-77.

Ashburner, M. 1971. Induction of puffs in polytene chromosomes of in vitro cultured salivary glands of Drosophila melanogaster by ecdysone and ecdysone analogues. Nat. New Biol. 230: 222-224.

Ashburner, M., Chihara, C., Meltzer, P., and Richards, G. 1974. Temporal control of puffing activity in polytene chromosomes. Cold Spring Harb. Symp. Quant. Biol. 38: 655-662.

Ayer, S., Walker, N., Mosammaparast, M., Nelson, J.P., Shilo, B.Z., and Benyajati, C. 1993. Activation and repression of Drosophila alcohol dehydrogenase distal transcription by two steroid hormone receptor superfamily members binding to a common response element. Nucleic Acids Res. 21: 1619-1627.

Baehrecke, E.H. 2002. How death shapes life during development. Nat. Rev. Mol. Cell Biol. 3: 779-787.

Baehrecke, E.H. and Thummel, C.S. 1995. The Drosophila E93 gene from the $93 \mathrm{~F}$ early puff displays stage- and tissue-specific regulation by 20-hydroxyecdysone. Dev. Biol. 171: $85-$ 97.

Baker, K.D., Warren, J.T., Thummel, C.S., Gilbert, L.I., and Mangelsdorf, D.J. 2000. Transcriptional activation of the Drosophila ecdysone receptor by insect and plant ecdysteroids. Insect Biochem. Mol. Biol. 30: 1037-1043.

Bayer, C.A., Holley, B., and Fristrom, J.W. 1996. A switch in Broad-complex zinc-finger isoform expression is regulated posttranscriptionally during the metamorphosis of Drosophila imaginal discs. Dev. Biol. 177: 1-14.

Bayer, C.A., von Kalm, L., and Fristrom, J.W. 1997. Relationships between protein isoforms and genetic functions demonstrate functional redundancy at the Broad-Complex during Drosophila metamorphosis. Dev. Biol. 187: 267-282.

Becker, H.J. 1959. Die puffs der speicheldrüsenchromosomen von Drosophila melanogaster. I. Beobachtungen zur ver- halten des puffmusters in normalstamm und bei zwei mutanten, giant und lethal-giant-larvae. Chromosoma 10: 654678.

Bender, M. 2003. Molecular mechanism of ecdysone action in insect development. In Encyclopedia of hormones (eds. H. Henry and A. Norman), Academic Press, New York (In press).

Bender, M., Imam, F.B., Talbot, W.S., Ganetzky, B., and Hogness, D.S. 1997. Drosophila ecdysone receptor mutations reveal functional differences among receptor isoforms. Cell 91: 777-788.

Bergamasco, R. and Horn, D. 1980. The biological activities of ecdysteroids and ecdysteroid analogues. In Progress in ecdysone research (ed. J. Hoffman), pp. 299-324. Elsevier, New York.

Bialecki, M., Shilton, A., Fichtenberg, C., Segraves, W., and Thummel, C. 2002. Loss of the ecdysteroid-inducible E75A orphan nuclear receptor uncouples molting from metamorphosis in Drosophila. Dev. Cell 3: 209-220.

Billas, I.M., Moulinier, L., Rochel, N., and Moras, D. 2001. Crystal structure of the ligand-binding domain of the Ultraspiracle protein USP, the ortholog of retinoid $\mathrm{X}$ receptors in insects. J. Biol. Chem. 276: 7465-7474.

Bishop, G.J. and Koncz, C. 2002. Brassinosteroids and plant steroid hormone signaling. Plant Cell 14: 97-110.

Bishop, G.J. and Yokota, T. 2001. Plants steroid hormones, brassinosteroids: Current highlights of molecular aspects on their synthesis/metabolism, transport, perception and response. Plant Cell Physiol. 42: 114-120.

Bishop, G.J., Harrison, K., and Jones, J.D. 1996. The tomato Dwarf gene isolated by heterologous transposon tagging encodes the first member of a new cytochrome P450 family. Plant Cell 8: 959-969.

Bishop, G.J., Nomura, T., Yokota, T., Harrison, K., Noguchi, T., Fujioka, S., Takatsuto, S., Jones, J.D., and Kamiya, Y. 1999. The tomato DWARF enzyme catalyses C-6 oxidation in brassinosteroid biosynthesis. Proc. Natl Acad. Sci. 96: 17611766.

Blais, C., Dauphin-Villemant, C., Kovganko, N., Girault, J.P., Descoins Jr., C., and Lafont, R. 1996. Evidence for the involvement of 3 -xo- $\delta 4$ intermediates in ecdysteroid biosynthesis. Biochem. J. 320: 413-419.

Burtis, K.C., Thummel, C.S., Jones, C.W., Karim, F.D., and Hogness, D.S. 1990. The Drosophila $74 E F$ early puff contains E74, a complex ecdysone-inducible gene that encodes two ets-related proteins. Cell 61: 85-99.

Cabrera y Poch, H.L., Peto, C.A., and Chory, J. 1993. A mutation in the Arabidopsis DET3 gene uncouples photoregulated leaf development from gene expression and chloroplast biogenesis. Plant J. 4: 671-682.

Cadigan, K.M. and Nusse, R. 1997. Wnt signaling: A common theme in animal development. Genes \& Dev. 11:32863305.

Champlin, D.T. and Truman, J.W. 1998. Ecdysteroid control of cell proliferation during optic lobe neurogenesis in the moth Manduca sexta. Development 125: 269-277.

- 2000. Ecdysteroid coordinates optic lobe neurogenesis via a nitric oxide signaling pathway. Development 127: 3543-3551.

Chavez, V.M., Marques, G., Delbecque, J.P., Kobayashi, K., Hollingsworth, M., Burr, J., Natzle, J.E., and O'Connor, M.B. 2000. The Drosophila disembodied gene controls late embryonic morphogenesis and codes for a cytochrome P450 enzyme that regulates embryonic ecdysone levels. Development 127: 4115-4126.

Cherbas, L., Yonge, C., Cherbas, P., and Williams, C. 1980. The 
morphological response of Kc-H cells to ecdysteroids: Hormonal specificity. Willhelm Roux's Arch. Dev. Biol. 189: 115.

Choe, S., Dilkes, B.P., Fujioka, S., Takatsuto, S., Sakurai, A., and Feldmann, K.A. 1998a. The DWF4 gene of Arabidopsis encodes a cytochrome P450 that mediates multiple $22 \alpha$-hydroxylation steps in brassinosteroid biosynthesis. Plant Cell 10: 231-243.

Choe, S., Fujioka, S., Tanaka, A., Tissier, C., Rossa, A., Noguchi, T., Takatsuto, S., Yoshidab, S., Taxa, F., and Feldmann, K. 1998b. Molecular cloning of Arabidopsis brassinosteroid biosynthetic genes DWF4, DWF5 and DWF7. In Abstracts of 9th International Conference on Arabidopsis Research pp. 555, University of Wisconsin-Madison, Madison, WI.

Choe, S., Dilkes, B.P., Gregory, B.D., Ross, A.S., Yuan, H., Noguchi, T., Fujioka, S., Takatsuto, S., Tanaka, A., Yoshida, S., et al. 1999a. The Arabidopsis dwarf1 mutant is defective in the conversion of 24-methylenecholesterol to campesterol in brassinosteroid biosynthesis. Plant Physiol. 119: 897-907.

Choe, S., Noguchi, T., Fujioka, S., Takatsuto, S., Tissier, C.P., Gregory, B.D., Ross, A.S., Tanaka, A., Yoshida, S., Tax, F.E., et al. 1999b. The Arabidopsis dwf7/ste1 mutant is defective in the $\delta 7$ sterol C-5 desaturation step leading to brassinosteroid biosynthesis. Plant Cell 11: 207-221.

Choe, S., Tanaka, A., Noguchi, T., Fujioka, S., Takatsuto, S., Ross, A.S., Tax, F.E., Yoshida, S., and Feldmann, K.A. 2000. Lesions in the sterol $\delta$ reductase gene of Arabidopsis cause dwarfism due to a block in brassinosteroid biosynthesis. Plant T. 21: 431-443.

Choe, S., Fujioka, S., Noguchi, T., Takatsuto, S., Yoshida, S., and Feldmann, K.A. 2001. Overexpression of DWARF4 in the brassinosteroid biosynthetic pathway results in increased vegetative growth and seed yield in Arabidopsis. Plant J. 26: 573-582.

Choi, Y.-H., Fujioka, S., Harada, A., Yokota, T., Takatsuto, S., and Sakurai, A. 1996. A brassinolide biosynthetic pathway via 6-deoxocastasterone. Phytochemistry 43: 593-596.

Choi, Y.-H., Fujioka, S., Nomura, T., Harada, A., Yokota, T., Takatsuto, S., and Sakurai, A. 1997. An alternative brassinolide biosynthetic pathway via late C6-oxidation. Phytochemistry 44: 609-613.

Chory, J., Nagpal, P., and Peto, C.A. 1991. Phenotypic and genetic analysis of $\operatorname{det} 2$, a new mutant that affects light-regulated seedling development in Arabidopsis. Plant Cell 3: 445-459.

Chory, J., Reinecke, D., Sim, S., Washburn, T., and Brenner, M. 1994. A role for cytokinins in de-etiolation in Arabodipsis: det mutants may have an altered response to cytokinins. Plant Physiol. 104: 339-347.

Clayton, G.M., Peak-Chew, S.Y., Evans, R.M., and Schwabe, J.W. 2001. The structure of the ultraspiracle ligand-binding domain reveals a nuclear receptor locked in an inactive conformation. Proc. Natl. Acad. Sci. 98: 1549-1554.

Clever, U. and Karlson, P. 1960. Induktion von puff-veränderungen in den speicheldrüsenchromosomen von Chironomus tentans durch ecdyson. Exp. Cell. Res. 20: 623-626.

Clouse, S.D. 1996. Molecular genetic studies confirm the role of brassinosteroids in plant growth and development. Plant $J$. 10: $1-8$

Clouse, S. and Sasse, J. 1998. Brassinosteroids: Essential regulators of plant growth and development. Annu. Rev. Plant Physiol. Plant Mol. Biol. 49: 427-451.

Clouse, S. and Zurek, D. 1991. Molecular analysis of brassinolide action in plant growth and development. In Brassinosteroids: Chemistry, bioactivity and applications (eds. $\mathrm{H}$.
Cutler, T. Yokota, and G. Adams), pp. 122-140. American Chemical Society, Washington, DC.

Clouse, S.D., Langford, M., and McMorris, T.C. 1996. A brassinosteroid-insensitive mutant in Arabidopsis thaliana exhibits multiple defects in growth and development. Plant Physiol. 111: 671-678.

Cutler, H.G., Yokota, T., and Adam, G., eds. 1991. Brassinosteroids. ACS Symposium Series pp. 474-496. American Chemical Society, Washington, DC..

D'Avino, P.P. and Thummel, C.S. 1998. crooked legs encodes a family of zinc finger proteins required for leg morphogenesis and ecdysone-regulated gene expression during Drosophila metamorphosis. Development 125: 1733-1745.

Descoins Jr., C. and Marion-Poll, F. 1999. Electrophysiological responses of gustatory sensilla of Mamestra brassicae larvae to three ecdysteroids: Ecdysone, 20-hydroxyecdysone and ponasterone A. J. Insect Phys. 45: 871-876.

DiBello, P.R., Withers, D.A., Bayer, C.A., Fristrom, J.W., and Guild, G.M. 1991. The Drosophila Broad-Complex encodes a family of related proteins containing zinc fingers. Genetics 129: 385-397.

Dinan, L. 1998. A strategy towards the elucidation of the contribution made by phytoecdysteroids to the deterrence of invertebrate predators on plants. Russ. J. Plant Phys. 45: 296-305.

- 2001. Phytoecdysteroids: Biological aspects. Phytochemistry 57: 325-339.

Dinan, L., Savchenko, T., and Whiting, P. 2001. On the distribution of phytoecdysteroids in plants. Cell. Mol. Life Sci. 58: 1121-1132.

Finbow, M.E. and Harrison, M.A. 1997. The vacuolar $\mathrm{H}^{+}$ATPase: A universal proton pump of eukaryotes. Biochem. I. 324: 697-712.

Fisk, G.J. and Thummel, C.S. 1995. Isolation, regulation, and DNA-binding properties of three Drosophila nuclear hormone receptor superfamily members. Proc. Natl. Acad. Sci. 92: 10604-10608.

FlyBase. 1999. The FlyBase database of the Drosophila genome projects and community literature. Nucleic Acids Res. 27: 85-88 http://flybase.bio.indiana.edu.

Friedrichsen, D. and Chory, J. 2001. Steroid signaling in plants: From the cell surface to the nucleus. Bioessays 23: 10281036.

Friedrichsen, D.M., Joazeiro, C.A., Li, J., Hunter, T., and Chory, J. 2000. Brassinosteroid-insensitive- 1 is a ubiquitously expressed leucine-rich repeat receptor serine/threonine kinase. Plant Physiol. 123: 1247-1256.

Friedrichsen, D., Nemhauser, J., Muramitsu, T., Maloof, J., Alonso, J., Ecker, J., Furuya, M., and Chory, J. 2002. Three redundant brassinosteroid early response genes encode putative bHLH transcription factors required for normal growth. Genetics (in press).

Fristrom, D. and Fristrom, J.W. 1993. The metamorphic development of the adult epidermis. In The Development of Drosophila melanogaster (eds. M. Bate and A. Martinez Arias), pp. 843-897. Cold Spring Harbor Laboratory Press, Cold Spring Harbor, NY.

Fujioka, S., Li, J., Choi, Y.H., Seto, H., Takatsuto, S., Noguchi, T., Watanabe, T., Kuriyama, H., Yokota, T., Chory, J., et al. 1997. The Arabidopsis deetiolated2 mutant is blocked early in brassinosteroid biosynthesis. Plant Cell 9: 1951-1962.

Gates, J. and Thummel, C.S. 2000. An enhancer trap screen for ecdysone-inducible genes required for Drosophila adult leg morphogenesis. Genetics 156: 1765-1776.

Gilbert, L.I., Rybczynski, R., and Warren, J.T. 2002. Control and biochemical nature of the ecdysteroidogenic pathway. 
Annu. Rev. Entomol. 47: 883-916.

Gotwals, P.J. and Fristrom, J.W. 1991. Three neighboring genes interact with the Broad-Complex and the Stubble-stubbloid locus to affect imaginal disc morphogenesis in Drosophila. Genetics 127: 747-759.

Grieneisen, M. 1994. Recent advances in our knowledge of ecdysteroid biosynthesis in insects and crustaceans. Insect Biochem. Mol. Biol. 24: 115-132.

Grieneisen, M.L., Warren, J.T., and Gilbert, L.I. 1993. Early steps in ecdysteroid biosynthesis: Evidence for the involvement of cytochrome P-450 enzymes. Insect Biochem. Mol. Biol. 23: 13-23.

He, Z., Wang, Z.Y., Li, J., Zhu, Q., Lamb, C., Ronald, P., and Chory, J. 2000. Perception of brassinosteroids by the extracellular domain of the receptor kinase BRI1. Science 288: 2360-2363.

He, J.X., Gendron, J.M., Yang, Y., Li, J., and Wang, Z.Y. 2002. The GSK3-like kinase BIN2 phosphorylates and destabilizes BZR1, a positive regulator of the brassinosteroid signaling pathway in Arabidopsis. Proc. Natl. Acad. Sci. 99: 1018510190.

Hewes, R.S., Schaefer, A.M., and Taghert, P.H. 2000. The cryptocephal gene (ATF4) encodes multiple basic-leucine zipper proteins controlling molting and metamorphosis in Drosophila. Genetics 155: 1711-1723.

Ho, M.N., Hill, K.J., Lindorfer, M.A., and Stevens, T.H. 1993. Isolation of vacuolar membrane $\mathrm{H}(+)$-ATPase-deficient yeast mutants; the VMA5 and VMA 4 genes are essential for assembly and activity of the vacuolar $\mathrm{H}(+)$-ATPase. J. Biol. Chem. 268: 221-227.

Hock, T., Cottrill, T., Keegan, J., and Garza, D. 2000. The E23 early gene of Drosophila encodes an ecdysone-inducible ATP-binding cassette transporter capable of repressing ecdysone-mediated gene activation. Proc. Natl. Acad. Sci. 97: 9519-9524.

Horner, M.A. and Thummel, C.S. 1997. Mutations in the DHR39 orphan receptor gene have no effect on viability. Drosoph. Inf. Serv. 80: 35-37.

Horner, M., Chen, T., and Thummel, C.S. 1995. Ecdysone regulation and DNA binding properties of Drosophila nuclear hormone receptor superfamily members. Dev. Biol. 168: 490-502.

Huelsken, J. and Birchmeier, W. 2001. New aspects of Wnt signaling pathways in higher vertebrates. Curr. Opin. Genet. Dev. 11: 547-553.

Hurban, P. and Thummel, C.S. 1993. Isolation and characterization of fifteen ecdysone-inducible Drosophila genes reveal unexpected complexities in ecdysone regulation. Mol Cell Biol 13: 7101-7111.

Ikebawa, N. and Zhao, Y.-J. 1981. Application of 24-epibrassinolide in agriculture. In Brassinosteroids; chemistry, bioactivity and applications (eds. H. Cutler, T. Yokota, and G. Adams), pp. 280-291. ACS Symposium Series, American Chemical Society, Washington, DC.

Imai, S., Toyosato, T., Sakai, M., Sato, Y., Fujioka, S., Murata, E., and Goto, M. 1969. Screening results of plants for phytoecdysones. Chem. Pharm. Bull. (Tokyo) 17: 335-339.

Iwasaki, T. and Shibaoka, H. 1991. Brassinosteroids act as regulators of tracheary-element differentiation in isolated Zinnia mesophyll cells. Plant Cell Physiol. 32: 1007-1014.

Jiang, C., Baehrecke, E.H., and Thummel, C.S. 1997. Steroid regulated programmed cell death during Drosophila metamorphosis. Development 124: 4673-4683.

Jochova, J., Zakeri, Z., and Lockshin, R.A. 1997. Rearrangement of the tubulin and actin cytoskeleton during programmed cell death in Drosophila salivary glands. Cell Death Differ.
4: 140-149.

Jones, C. and Firn, R. 1978. A role of phytoecdysteroids in bracken fern, Pteridium aquilinum (L.) Kuhn, as a defence against phytophagous insect attack. J. Chem. Ecol. 4: 117138.

Jones, G., Wozniak, M., Chu, Y., Dhar, S., and Jones, D. 2001. Juvenile hormone III-dependent conformational changes of the nuclear receptor ultraspiracle. Insect Biochem. Mol. Biol. 32: 33-49.

Jürgens, G., Wieschaus, E., Nüsslein-Volhard, C., and Kluding, H. 1984. Mutations affecting the pattern of the larval cuticle in Drosophila melanogaster. II. Zygotic loci on the third chromosome. Roux's Arch. Dev. Biol. 193: 283-295.

Kang, J.G., Yun, J., Kim, D.H., Chung, K.S., Fujioka, S., Kim, J.I., Dae, H.W., Yoshida, S., Takatsuto, S., Song, P.S., et al. 2001. Light and brassinosteroid signals are integrated via a darkinduced small $\mathrm{G}$ protein in etiolated seedling growth. Cell 105: 625-636.

Karim, F.D. and Thummel, C.S. 1992. Temporal coordination of regulatory gene expression by the steroid hormone ecdysone. EMBO J. 11: 4083-4093.

Kauschmann, A., Jessop, A., Koncz, C., Szekeres, M., Willmitzer, L., and Altmann, T. 1996. Genetic evidence for an essential role of brassinosteroids in plant development. Plant J. 9: 701-713.

Klahre, U., Noguchi, T., Fujioka, S., Takatsuto, S., Yokota, T., Nomura, T., Yoshida, S., and Chua, N.H. 1998. The Arabidopsis DIMINUTO/DWARF1 gene encodes a protein involved in steroid synthesis. Plant Cell 10: 1677-1690.

Koelle, M.R., Talbot, W.S., Segraves, W.A., Bender, M.T., Cherbas, P., and Hogness, D.S. 1991. The Drosophila EcR gene encodes an ecdysone receptor, a new member of the steroid receptor superfamily. Cell 67: 59-77.

Koelle, M.R., Segraves, W.A., and Hogness, D.S. 1992. DHR3: A Drosophila steroid receptor homolog. Proc. Natl. Acad. Sci. 89: 6167-6171.

Koka, C.V., Cerny, R.E., Gardner, R.G., Noguchi, T., Fujioka, S., Takatsuto, S., Yoshida, S., and Clouse, S.D. 2000. A putative role for the tomato genes DUMPY and CURL-3 in brassinosteroid biosynthesis and response. Plant Physiol. 122: 85-98.

Lafont, R., Bouthier, A., and Wilson, I. 1991. Phytoecdysteroids: Structures, occurrence, biosynthesis and possible ecological significance. In Insect chemical ecology (ed. I. Hardy), pp. 197-214. Academica Prague, Prague, Czechoslovakia.

Lam, G., Hall, B.L., Bender, M., and Thummel, C.S. 1999. DHR3 is required for the prepupal-pupal transition and differentiation of adult structures during Drosophila metamorphosis. Dev. Biol. 212: 204-216.

Lee, C.Y. and Baehrecke, E.H. 2001. Steroid regulation of autophagic programmed cell death during development. Development 128: 1443-1455.

Li, J. and Chory, J. 1997. A putative leucine-rich repeat receptor kinase involved in brassinosteroid signal transduction. Cell 90: 929-938.

Li, J. and Nam, K.H. 2002. Regulation of brassinosteroid signaling by a GSK3/SHAGGY-like kinase. Science 295: 1299-1301.

Li, J., Nagpal, P., Vitart, V., McMorris, T.C., and Chory, J. 1996. A role for brassinosteroids in light-dependent development of Arabidopsis. Science 272: 398-401.

Li, J., Biswas, M.G., Chao, A., Russell, D.W., and Chory, J. 1997. Conservation of function between mammalian and plant steroid 5 $\alpha$-reductases. Proc. Natl. Acad. Sci. 94: 3554-3559.

Li, J., Lease, K.A., Tax, F.E., and Walker, J.C. 2001a. BRS1, a serine carboxypeptidase, regulates BRIl signaling in Arabidopsis thaliana. Proc. Natl. Acad. Sci. 98: 5916-5921. 
Li, J., Nam, K.H., Vafeados, D., and Chory, J. 2001b. Bin2, a new brassinosteroid-insensitive locus in Arabidopsis. Plant Physiol. 127: 14-22.

Li, J., Wen, J., Lease, K.A., Doke, J.T., Tax, F.E., and Walker, J.C. 2002. BAK1, an Arabidopsis LRR receptor-like protein kinase, interacts with BRI1 and modulates brassinosteroid signaling. Cell 110: 213-222.

Mandava, N.B. 1988. Plant growth-promoting brassinosteroids. Ann. Rev. Plant Physiol. Plant Mol. Biol. 39: 23-52.

Mathur, J., Molnar, G., Fujioka, S., Takatsuto, S., Sakurai, A., Yokota, T., Adam, G., Voigt, B., Nagy, F., Maas, C., et al. 1998. Transcription of the Arabidopsis CPD gene, encoding a steroidogenic cytochrome P450, is negatively controlled by brassinosteroids. Plant J. 14: 593-602.

Meyerowitz, E.M. 2002. Plants compared to animals: The broadest comparative study of development. Science 295: $1482-1485$.

Millar, A., Straume, M., Chory, J., Chua, N.-H., and Kay, S. 1995. The regulation or circadian period by phototransduction pathways in Arabidopsis. Science 267: 1163-1166.

Mussig, C., Fischer, S., and Altmann, T. 2002. Brassinosteroidregulated gene expression. Plant Physiol. 129: 1241-1251.

Nam, K.H. and Li, J. 2002. BRI1/BAK1, a receptor kinase pair mediating brassinosteroid signaling. Cell 110: 203-212.

Neff, M.M., Nguyen, S.M., Malancharuvil, E.J., Fujioka, S., Noguchi, T., Seto, H., Tsubuki, M., Honda, T., Takatsuto, S., Yoshida, S., et al. 1999. BAS1: A gene regulating brassinosteroid levels and light responsiveness in Arabidopsis. Proc. Natl. Acad. Sci. 96: 15316-15323.

Noguchi, T., Fujioka, S., Choe, S., Takatsuto, S., Yoshida, S., Yuan, H., Feldmann, K.A., and Tax, F.E. 1999. Brassinosteroid-insensitive dwarf mutants of Arabidopsis accumulate brassinosteroids. Plant Physiol. 121: 743-752.

Noguchi, T., Fujioka, S., Choe, S., Takatsuto, S., Tax, F.E., Yoshida, S., and Feldmann, K.A. 2000. Biosynthetic pathways of brassinolide in Arabidopsis. Plant Physiol. 124: 201-209.

Nomura, T., Kitasaka, Y., Takatsuto, S., Reid, J.B., Fukami, M., and Yokota, T. 1999. Brassinosteroid/Sterol synthesis and plant growth as affected by $l k a$ and $l k b$ mutations of pea. Plant Physiol. 119: 1517-1526.

Nüsslein-Volhard, C., Wieschaus, E., and Kluding, H. 1984. Mutations affecting the pattern of the larval cuticle in Drosophila melanogaster. I. Zygotic loci on the second chromosome. Roux's Arch. Dev. Biol. 183: 267-282.

Oh, M.-H., Romanow, W., Smith, R., Zamski, E., Sasse, J., and Clouse, S. 1998. Soybean BRU1 encodes a functional xyloglucan endotransglycosylase that is highly expressed in inner epicotyl tissues during brassinosteroid-promoted elongation. Plant Cell Physiol. 39.

Oh, M.H., Ray, W.K., Huber, S.C., Asara, J.M., Gage, D.A., and Clouse, S.D. 2000. Recombinant brassinosteroid insensitive 1 receptor-like kinase autophosphorylates on serine and threonine residues and phosphorylates a conserved peptide motif in vitro. Plant Physiol. 124: 751-766.

Ohno, C.K. and Petkovich, M. 1993. FTZ-F1 $\beta$, a novel member of the Drosophila nuclear receptor family. Mech. Dev. 40: $13-24$.

Pecasse, F., Beck, Y., Ruiz, C., and Richards, G. 2000. Kruppelhomolog, a stage-specific modulator of the prepupal ecdysone response, is essential for Drosophila metamorphosis. Dev. Biol. 221: 53-67.

Perez-Perez, J.M., Ponce, M.R., and Micol, J.L. 2002. The UCU1 Arabidopsis gene encodes a SHAGGY/GSK3-like kinase required for cell expansion along the proximodistal axis. Dev. Biol. 242: 161-173.
Rees, H. 1995. Ecdysteroid biosynthesis and inactivation in relation to function. Eur. J. Entomol. 92: 9-39.

Renault, N., King-Jones, K., and Lehmann, M. 2001. Downregulation of the tissue-specific transcription factor Fork head by Broad-Complex mediates a stage-specific hormone response. Development 128: 3729-3737.

Restifo, L.L. and Wilson, T.G. 1998. A juvenile hormone agonist reveals distinct developmental pathways mediated by ecdysone-inducible Broad Complex transcription factors. Dev. Genet. 22: 141-159.

Richards, G. 1976. Sequential gene activation by ecdysone in polytene chromosomes of Drosophila melanogaster. IV. The mid-prepupal period. Dev. Biol. 54: 256-263.

1981. The radioimmune assay of ecdysteroid titres in Drosophila melanogaster. Mol. Cell. Endocrinol. 21: 181197.

- 1997. The ecdysone regulatory cascades in Drosophila. Adv. in Dev. Biol. 5: 81-135.

Riddiford, L.M. 1993. Hormones and Drosophila development. In The Development of Drosophila melanogaster (eds. M. Bate and A. Martinez-Arias), pp. 899-939. Cold Spring Harbor Laboratory Press, Cold Spring Harbor, NY.

Riddiford, L. 1996. Molecular aspects of juvenile hormone action in insect metamorphosis. In Metamorphosis: Postembryonic reprogramming of gene expression in amphibian and insect cells (eds. L. Gilbert, J. Tata, and B. Atkinson), pp. 223-251. Academic Press, New York.

Riddiford, L.M., Cherbas, P., and Truman, J.W. 2000. Ecdysone receptors and their biological actions. Vitam. Horm. 60: 173.

Roberts, K. and McCann, M.C. 2000. Xylogenesis: The birth of a corpse. Curr. Opin. Plant. Biol. 3: 517-522.

Robertson, C.W. 1936. The metamorphosis of Drosophila melanogaster, including an accurately timed account of the principal morphological changes. J. Morphol. 59: 351-399.

Rouleau, M., Marsolais, F., Richard, M., Nicolle, L., Voigt, B., Adam, G., and Varin, L. 1999. Inactivation of brassinosteroid biological activity by a salicylate-inducible steroid sulfotransferase from Brassica napus. J. Biol. Chem. 274: 2092520930.

Russell, S. and Ashburner, M. 1996. Ecdysone-regulated chromosome puffing in Drosophila melanogaster. In Metamorphosis. Postembryonic reprogramming of gene expression in amphibian and insect cells (eds. B.G. Atkinson, L.I. Gilbert, and J.R. Tata), pp. 109-144. Academic Press, New York.

Russell, D.W. and Wilson, J.D. 1994. Steroid 5a-reductase: Two genes/two enzymes. Annu. Rev. Biochem. 63: 25-61.

Russell, S.R., Heimbeck, G., Goddard, C.M., Carpenter, A.T., and Ashburner, M. 1996. The Drosophila Eip78C gene is not vital but has a role in regulating chromosome puffs. Genetics 144: 159-170.

Sakurai, A. and Fujioka, S. 1997. Studies on biosynthesis of brassinosteroids. Biosci. Biotechnol. Biochem. 61: 757-762.

Schmelz, E., Grebenok, R., Galbraith, D., and Bowers, W. 1998. Damage-induced accumulation of phytoecdysteroids in spinach: A rapid root response involving the octadecanoic acid pathway. J. Chem. Ecol. 24: 339-360.

Schmelz, E., Grebenok, R., Galbraith, D., and Bowers, W. 1999. Insect-induced synthesis of phyecdysteroids in spinach, Spinacia oleracea. J. Chem. Ecol. 25: 1739-1757.

Schumacher, K., Vafeados, D., McCarthy, M., Sze, H., Wilkins, T., and Chory, J. 1999. The Arabidopsis det3 mutant reveals a central role for the vacuolar $\mathrm{H}(+)$-ATPase in plant growth and development. Genes \& Dev. 13: 3259-3270.

Segraves, W. 1998. Ecdysone response in Drosophila. In Hormones and growth factors in development and neoplasia 
(eds. R. Dickson and D. Salomon), pp. 45-78. John Wiley \& Sons, New York.

Segraves, W.A. and Hogness, D.S. 1990. The E75 ecdysone-inducible gene responsible for the 75B early puff in Drosophila encodes two new members of the steroid receptor superfamily. Genes \& Dev. 4: 204-219.

Sharpe, C., Lawrence, N., and Martinez Arias, A. 2001. Wnt signalling: A theme with nuclear variations. Bioessays 23: $311-318$.

Siegmund, T. and Lehmann, M. 2002. The Drosophila Pipsqueak protein defines a new family of helix-turn-helix DNA-binding proteins. Dev. Genes Evol. 212: 152-157.

Song, Q. and Gilbert, L.I. 1998. Alterations in ultraspiracle (USP) content and phosphorylation state accompany feedback regulation of ecdysone synthesis in the insect prothoracic gland. Insect Biochem. Mol. Biol. 28: 849-860.

Stone, B.L. and Thummel, C.S. 1993. The Drosophila $78 \mathrm{C}$ early late puff contains $E 78$, an ecdysone-inducible gene that encodes a novel member of the nuclear hormone receptor superfamily. Cell 75: 307-320.

Strott, C.A. 1996. Steroid sulfotransferases. Endocr. Rev. 17: 670-697.

Szekeres, M., Nemeth, K., Koncz-Kalman, Z., Mathur, J., Kauschmann, A., Altmann, T., Redei, G.P., Nagy, F., Schell, J., and Koncz, C. 1996. Brassinosteroids rescue the deficiency of CYP90, a cytochrome P450, controlling cell elongation and deetiolation in Arabidopsis. Cell 85: 171-182.

Tanaka, Y., Asaoka, K., and Takeda, S. 1994. Different feeding and gustatory responses to ecdysone and 20-hydroxyecdysone by larvae of the silkworm, Bombyx mori. J. Chem. Ecol. 20: 125-133.

The Arabidopsis Genome Initiative. 2000. Analysis of the genome sequence of the flowering plant Arabidopsis thaliana. Nature 408: 796-815.

Thomas, H.E., Stunnenberg, H.G., and Stewart, A.F. 1993. Heterodimerization of the Drosophila ecdysone receptor with retinoid X receptor and ultraspiracle. Nature 362: 471-475.

Thummel, C.S. 1995. From embryogenesis to metamorphosis: The regulation and function of Drosophila nuclear receptor superfamily members. Cell 83: 871-877.

. 1996. Flies on steroids-Drosophila metamorphosis and the mechanisms of steroid hormone action. Trends Genet. 12: $306-310$.

von Kalm, L., Fristrom, D., and Fristrom, J. 1995. The making of a fly leg: A model for epithelial morphogenesis. Bioessays 17: 693-702.

Wang, Z.Y., Seto, H., Fujioka, S., Yoshida, S., and Chory, J. 2001. BRI1 is a critical component of a plasma-membrane receptor for plant steroids. Nature 410: 380-383.

Wang, Z.Y., Nakano, T., Gendron, J., He, J., Chen, M., Vafeados, D., Yang, Y., Fujioka, S., Yoshida, S., Asami, T., et al. 2002. Nuclear-localized BZR1 mediates brassinosteroid-induced growth and feedback suppression of brassinosteroid biosynthesis. Dev.Cell 2: 505-513.

Warren, J.T., Bachmann, J.S., Dai, J.D., and Gilbert, L.I. 1996. Differential incorporation of cholesterol and cholesterol derivatives into ecdysteroids by the larval ring glands and adult ovaries of Drosophila melanogaster: A putative explanation for the 1(3)ecd1 mutation. Insect Biochem. Mol. Biol. 26: $931-943$.

Warren, J.T., Petryk, A., Marques, G., Jarcho, M., Parvy, J.P., Dauphin-Villemant, C., O'Connor, M.B., and Gilbert, L.I. 2002. Molecular and biochemical characterization of two P450 enzymes in the ecdysteroidogenic pathway of Drosophila melanogaster. Proc. Natl. Acad. Sci. 99: 1104311048.
White, K.P., Hurban, P., Watanabe, T., and Hogness, D.S. 1997. Coordination of Drosophila metamorphosis by two ecdysone-induced nuclear receptors. Science 276: 114-117.

White, K.P., Rifkin, S.A., Hurban, P., and Hogness, D.S. 1999. Microarray analysis of Drosophila development during metamorphosis. Science 286: 2179-2184.

Wieschaus, E., Nüsslein-Volhard, C., and Jürgens, G. 1984. Mutations affecting the pattern of the larval cuticle in Drosophila melanogaster. III. Zygotic loci on the X-chromosome and fourth chromosome. Roux's Arch. Dev. Biol. 193: 296307.

Winter, J., Bilbe, G., Richener, H., Sehringer, B., and Kayser, H. 1999. Cloning of a cDNA encoding a novel cytochrome P450 from the insect Locusta migratoria: CYP6H1, a putative ecdysone 20-h-ydroxylase. Biochem. Biophys. Res. Commun. 259: 305-310.

Woodgett, J.R. 2001. Judging a protein by more than its name: gsk-3. Sci. STKE 2001: RE12.

Xu, W., Purugganan, M.M., Polisensky, D.H., Antosiewicz, D.M., Fry, S.C., and Braam, J. 1995. Arabidopsis TCH4, regulated by hormones and the environment, encodes a xyloglucan endotransglycosylase. Plant Cell 7: 1555-1567.

Yamamoto, R., Fujioka, S., Demura, T., Takatsuto, S., Yoshida, S., and Fukuda, H. 2001. Brassinosteroid levels increase drastically prior to morphogenesis of tracheary elements. Plant Physiol. 125: 556-563.

Yamamuro, C., Ihara, Y., Wu, X., Noguchi, T., Fujioka, S., Takatsuto, S., Ashikari, M., Kitano, H., and Matsuoka, M. 2000. Loss of function of a rice brassinosteroid insensitive 1 homolog prevents internode elongation and bending of the lamina joint. Plant Cell 12: 1591-1606.

Yao, T., Segraves, W.A., Oro, A.E., McKeown, M., and Evans, R.M. 1992. Drosophila ultraspiracle modulates ecdysone receptor function via heterodimer formation. Cell 71: 63-72.

Yao, T., Forman, B.M., Jiang, Z., Cherbas, L., Chen, J.D., McKeown, M., Cherbas, P., and Evans, R.M. 1993. Functional ecdysone receptor is the product of $E c R$ and ultraspiracle genes. Nature 366: 476-479.

Yin, Y., Wang, Z.Y., Mora-Garcia, S., Li, J., Yoshida, S., Asami, T., and Chory, J. 2002. BES1 accumulates in the nucleus in response to brassinosteroids to regulate gene expression and promote stem elongation. Cell 109: 181-191.

Zhou, X. and Riddiford, L.M. 2002. Broad specifies pupal development and mediates the "status quo" action of juvenile hormone on the pupal-adult transformation in Drosophila and Manduca. Development 129: 2259-2269.

Zurek, D.M. and Clouse, S.D. 1994. Molecular cloning and characterization of a brassinosteroid-regulated gene from elongating soybean (Glycine max L.) epicotyls. Plant Physiol. 104: $161-170$

Zurek, D.M., Rayle, D.L., McMorris, T.C., and Clouse, S.D. 1994. Investigation of gene expression, growth kinetics, and wall extensibility during brassinosteriod-regulated stem elongation. Plant Physiol. 104: 505-513. 


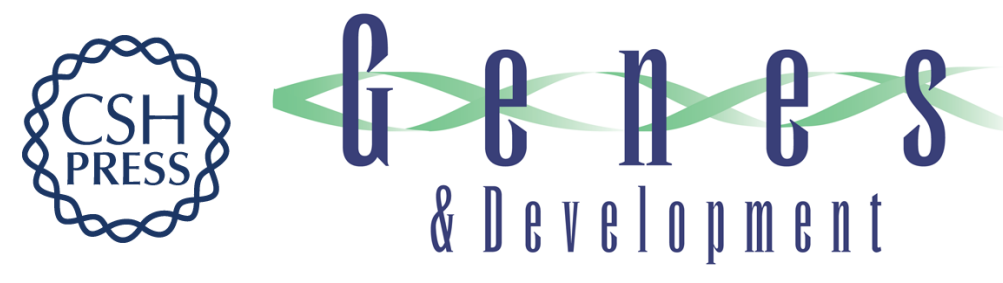

\section{Steroid signaling in plants and insects--common themes, different pathways}

Carl S. Thummel and Joanne Chory

Genes Dev. 2002, 16:

Access the most recent version at doi:10.1101/gad.1042102

References This article cites 141 articles, 61 of which can be accessed free at: http://genesdev.cshlp.org/content/16/24/3113.full.html\#ref-list-1

License

Email Alerting Receive free email alerts when new articles cite this article - sign up in the box at the top Service right corner of the article or click here.

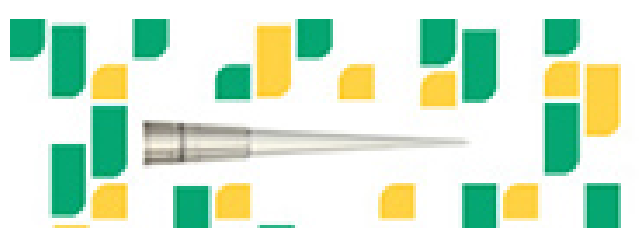

Focused on your science. 